Research Article

\title{
Seismic Performance of Offshore Piers under Wave Impact and Chloride Ion Corrosion Environment
}

\author{
Yin Gu $(\mathbb{D}$, Anhua Yu $\mathbb{D}$, and Xiaolong Zhang \\ College of Civil Engineering, Fuzhou University, Fuzhou 350108, China \\ Correspondence should be addressed to Yin Gu; cinoa@fzu.edu.cn
}

Received 15 June 2021; Accepted 9 September 2021; Published 30 December 2021

Academic Editor: Piguang Wang

Copyright ( $) 2021$ Yin Gu et al. This is an open access article distributed under the Creative Commons Attribution License, which permits unrestricted use, distribution, and reproduction in any medium, provided the original work is properly cited.

\begin{abstract}
Offshore bridges may suffer from chloride ion corrosion, tsunami wave impact, and earthquake. However, the coupling effects of multiple factors have not been fully considered. This paper studied multiple degradation effects on the seismic performance of offshore piers considering tsunami wave impact, chloride ion corrosion, and their interaction. Firstly, through the scale model test of tsunami wave flume, the wave force of box girder structures and piers under different tsunami wave conditions is measured. Then, according to the corrosion characteristics of coastal chloride salts on reinforced concrete bridge piers, the corrosion parameters is selected by Latin hypercube sampling, and the influence of corrosion expansion and cracking of bridge pier cover on the chloride ion corrosion process is considered to modify the degradation model of corroded reinforced concrete materials. Finally, the wave load measured by the test is converted by the similarity criterion of the fluid mechanic test and loaded into the ABAQUS full-bridge model, and the pier after the tsunami wave is evaluated by the pushover analysis. The bearing capacity and lateral stiffness of the corroded pier before and after different tsunami waves are compared. The results show that the lateral bearing capacity and stiffness of bridge piers are, respectively, decreased by $27.6 \%$ and $6.2 \%$ after 30 years of service. Without corrosion, the lateral bearing capacity and stiffness of piers were, respectively, reduced by $11.45 \%$ and $10.6 \%$ after HXB-5 wave impact. After 30 years of service, the lateral bearing capacity and stiffness of bridge piers are, respectively, reduced by $41.8 \%$ and $22.5 \%$ under the combined action of corrosion and HXB-5 wave impact. It is found that the coupling effects of multiple degradation factors were more significant than the simple superposition ones. Therefore, the coupling effect of multiple factors should be considered in practical engineering.
\end{abstract}

\section{Introduction}

Bridges play an essential role in the transportation network. During the whole service period, the structure will deteriorate due to aging, regular operation, or extreme load/environmental conditions. Generally, there are two types of degradation in most bridge structures: gradual degradation (such as corrosion, alkali-silica reaction, fatigue, and crack growth) and rapid degradation (such as damage caused by natural or man-made disasters such as earthquake, hurricane, flood, and explosion) [1-3]. Degradation is a severe problem in bridge engineering, which will significantly reduce the service life and reliability of the bridge. Most existing studies focus on the degradation of a single measurement standard. The degradation increment assumed by these studies is usually purely dependent on age/time. It should be noted that the increment may also largely depend on the structural state. There have been many studies on the performance evaluation of offshore reinforced concrete bridges under single natural risk. However, due to the complexity of the structure environment, it is necessary to consider the degradation caused by multiple factors, so as to evaluate the seismic performance of the structure more accurately [4]. The research of reinforced concrete bridges under multiple degradation processes and their coupling effects is still in its infancy, so it is of great significance to study the seismic performance of offshore reinforced concrete bridge piers under the impact of the tsunami wave.

During a tsunami, it is necessary to determine the waveinduced load on the superstructure of a bridge. The vertical layout and cross section of bridge superstructure are diverse, so it is difficult to have a unified wave force calculation 
model, so the direct test of wave force is the most effective method to evaluate the magnitude and law of wave force on bridge structure [5-7]. Cuomo et al. [5] measured the wave force and pressure of the wharf with the protruding structure on a 1:25 scale model and studied the physical loading process in the test, which provided new guidance for the design of wave load on the main girder. Guo et al. [6] used a $1: 10$ full-bridge model for experimental research and compared the test results with the two theoretical calculation models proposed in Douglass and AASHTO guidelines, which further improved the accuracy of the theoretical model. Most of the research object is the girder of the bridge, and the girder is erected on the pier through the support. The bridge type with a strong connection between the pier and the girder, such as rigid frame bridge, is relatively less.

Chloride ion erosion is the leading cause of steel corrosion in the offshore environment [8]. Therefore, most scholars study the seismic performance of reinforced concrete bridges combined with the chloride ion erosion process $[9,10]$. Jia et al. [9] studied the seismic performance of low corrosion piers from offshore bridges that have been in service for more than 20 years. The results show that although the corrosion degree of the tested column is low, the area of corroded longitudinal reinforcement and the displacement ductility decreases obviously due to the weakening of the restraint of corroded transverse reinforcement. Dong et al. [11] used explicit dynamic software LS-DYNA to study the effect factors of the impact on the mechanical behavior of corroded reinforced concrete bridge piers subjected to corrosion in the marine environment. The results show that the increase of the diameter for the main rebar can improve the anti-impact properties of the bridge pier. The increase in the rate of main reinforcement corrosion and impact velocity will reduce the anti-impact properties of piers. The diameter of the stirrup rebar has less influence on the anti-impact mechanical properties of the bridge pier. Lin and Zhao [12] established the finite element model of piers with different corrosion degrees based on OpenSees finite element software and studied the seismic performance and seismic failure mode of each pier model. The results show that the bearing capacity and cumulative energy consumption of the nonuniform corrosion pier along with the pier height decrease with the increase of corrosion degree; the seismic failure mode of the corroded pier will change, as its plastic hinge position will transfer from the column end to the bottom of the splash and tidal zone. Stephens et al. [13] predicted the damage susceptibility of reinforced concrete (RC) and concrete-filled steel tube (CFST) bridges subjected to seismic and tsunami loading scenarios by using the open-source structural analysis software OpenSees and the open-source computation fluid dynamics software OpenFOAM. For the seismic hazard analysis, a suite of near-field ground motions was scaled to predict the representative response of the two structures to a maximum considered seismic event (MCE). In parallel, a series of tsunami loading scenarios, including bore-type tsunami impact and rising steady-state flows, were developed using OpenFOAM models; these loading scenarios were applied to the structural models in OpenSees to evaluate the performance of the structures for a tsunamionly loading scenario to allow for a direct comparison of the seismic and tsunami demands and response. The results show that both structures adequately resisted the MCE seismic hazard but demonstrated a high collapse potential for all tsunami loading scenarios. Akiyama et al. [10] analyzed the progress of structural design methodology from the deterministic allowable stress design (ASD) toward the life-cycle-based design and evaluation of bridges and bridge networks under various dangerous situations. Focusing on earthquake, tsunami, and corrosion degradation, the concepts and methods of single bridge and bridge network are described. It is suggested to further study and improve the reliability and risk assessment framework of bridges under multiple independent or coupled hazards. The research on chloride corrosion of reinforced concrete structures has been gradually mature, but the seismic performance degradation of structures under multifactor action is still in its infancy.

This paper studies the influence of multiple degradations on the seismic performance of offshore piers from the perspective of tsunami wave impact, chloride ion corrosion, and their interaction. Firstly, through the scale model test of tsunami wave flume, the wave force of box girder structure and pier under different tsunami wave conditions is measured. Then, according to the corrosion characteristics of coastal chloride salts on reinforced concrete bridge piers, the corrosion parameters were selected by Latin hypercube sampling, and the influence of corrosion expansion and cracking of bridge pier cover on the chloride ion corrosion process was considered to modify the degradation model of corroded reinforced concrete materials. Finally, the wave load measured by the test is converted by the similarity criterion of the fluid mechanic test and loaded into the ABAQUS full-bridge model, and the pier after the tsunami wave is analyzed by the pushover analysis. The bearing capacity and lateral stiffness of the corroded pier before and after different tsunami waves are compared.

\section{Wave Force Test of Wave Impact on the Bridge Structure}

2.1. Engineering Background. The main bridge is a threespan concrete continuous rigid frame bridge with a span of $3 \times 20 \mathrm{~m}$. The upper part is a streamlined box girder with a deck width of $10 \mathrm{~m}$. The lower part is a circular pier with a diameter of $1.6 \mathrm{~m}$ and a height of $8 \mathrm{~m}$. The elevation of the bottom of the pier is consistent with that of the seabed. The pile foundation is a circular single-column pile with a diameter of $2.0 \mathrm{~m}$ and a pile height of $41.5 \mathrm{~m}$. C40 and C30 concrete are used for pier and pile foundation, respectively. The general layout of the bridge type and the schematic diagram of the section size of the upper box girder of the bridge are shown in Figures 1 and 2, respectively.

2.2. Model Making and Parameter Setting. According to the Froude similarity criterion, the scale of the box girder test model is $1: 25$. The test model is printed by a $3 \mathrm{D}$ printer, and 


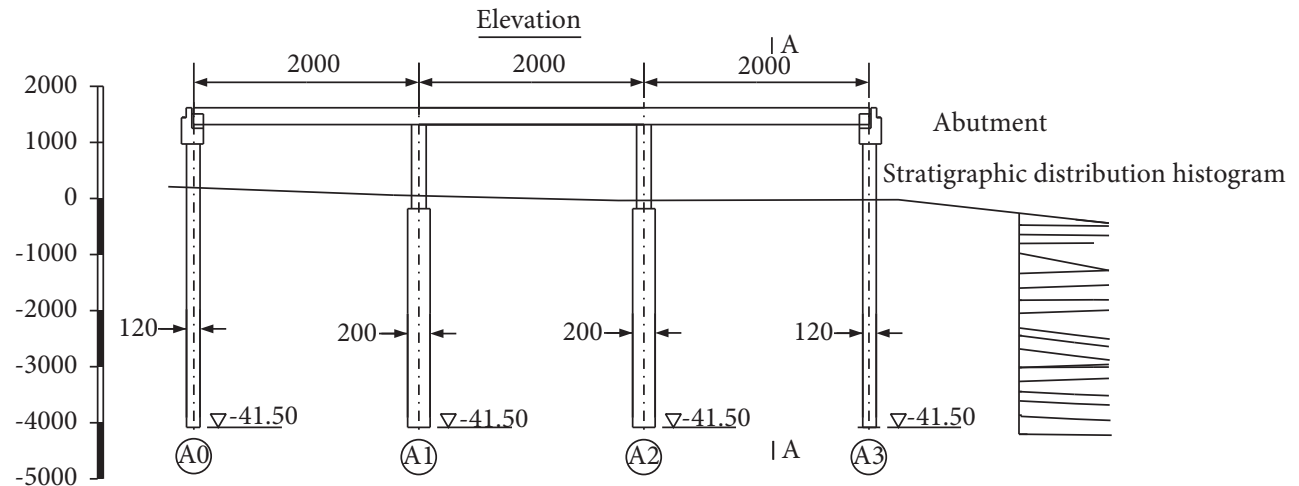

(a)

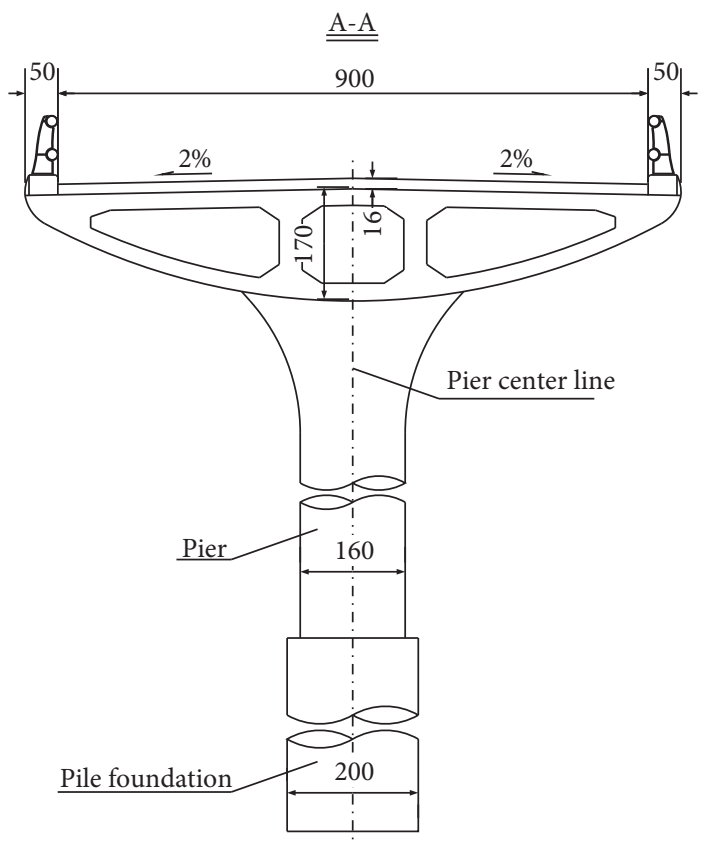

(b)

Figure 1: General layout of the bridge (unit: $\mathrm{cm}$ ). (a) Bridge elevation map. (b) A-A cross section.

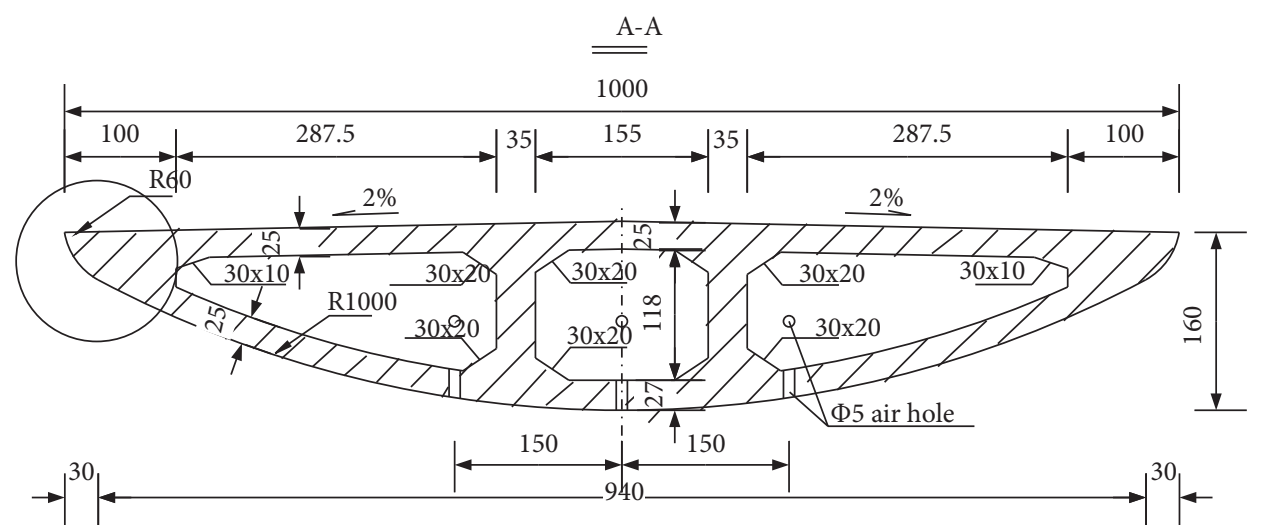

FIGURE 2: Diagram of section size of upper box girder of the bridge (unit: $\mathrm{cm}$ ). 
the dimensions are as follows: the beam length is $0.9 \mathrm{~m}$, the beam width is $0.4 \mathrm{~m}$, the beam height is $0.07 \mathrm{~m}$, the pier height is $0.13 \mathrm{~m}$, and the pier diameter is $0.064 \mathrm{~m}$. It should be noted that the submergence coefficient $C_{S}$ under wave impact is defined as the ratio of the height of wave crest exceeding the beam bottom $z$ to the beam height $H_{\mathrm{b}}$, as shown in Figure 3.

\subsection{Test Model Installation and Sensor Arrangement.} After printing the test model, the reinforced concrete is poured inside for splicing reinforcement. The layout of the reinforced model and pressure sensor points is shown in Figure 4. It should be noted that the installation direction of the sensor is the normal direction outside the structure surface.

The tsunami wave test is carried out in the water conservancy building of Fuzhou University. Figure 5 shows the test flume. The tsunami wave in the test tank is simulated based on the principle of dam break wave, as shown in Figure 6. In order to obtain the wave height and velocity required by the test, two wave gauges are set in the main water tank. The distance between the wave gauges is $1 \mathrm{~m}$, and the distance between the model and the closer wave gauge is $1 \mathrm{~m}$. The average value of the wave height measured by the two wave gauges is taken as the wave height required for the test. The distance between the two wave gauges divided by the time difference of the tsunami wave passing through the two wave gauges is regarded as the wave velocity.

The process of tsunami wave test is as follows: firstly, the water level $W(0.5 \mathrm{~m}, 0.6 \mathrm{~m}, 0.7 \mathrm{~m})$ and the gate opening height $G(0.25 \mathrm{~m}, 0.3 \mathrm{~m}, 0.35 \mathrm{~m}, 0.4 \mathrm{~m}, 0.45 \mathrm{~m})$ of the reservoir are used to generate 15 kinds of tsunami waves under different conditions, and each condition is measured 5-6 times. Then, the maximum and minimum values of wave height and wave velocity are removed from the measured wave height and wave velocity in each condition, and the remaining measured values are averaged to obtain the ideal wave height $h$ and wave velocity $u$. Finally, the test results of tsunami wave parameters under different conditions are shown in Table 1 . It should be noted that the similarity ratio of the box girder prototype and model parameters is shown in Table 2.

\section{Degradation Model of Reinforced Concrete Materials in Chloride Corrosion Environment}

\subsection{Start Time and Current Density of Rebar Corrosion}

3.1.1. Starting Time of Rebar Corrosion. Assume that the chloride ion concentration is 0 at $t=0$ and the surface chloride ion concentration $C_{0}$ is a constant during the exposure period. With the penetration of chloride ion, the chloride ion concentration reaches a certain threshold concentration $C_{\text {crit. }}$. At this time, the one-dimensional theoretical simplified $T_{\text {init }}$ calculation formula for the initial corrosion time of reinforcement is obtained [14].

$$
T_{\text {init }}=\left\{\frac{c^{2}}{4 D_{c}}\left[\operatorname{erf}^{-1}\left(\frac{C_{0}-C_{\text {crit }}}{C_{0}}\right)\right]^{-2}\right\}^{(1 /(1-n))},
$$

where $c$ is the thickness of concrete cover $(\mathrm{mm}), C_{\text {crit }}$ is the critical chloride ion concentration $\left(\mathrm{kg} / \mathrm{m}^{3}\right)$ for the dissolution of passive film on the surface of steel bar, $D_{c}$ is the diffusion coefficient of surface chloride ion, and $n$ is the time index and is taken as 0.2 .

Li [15] sorted out and calculated the research results of some relevant researchers and gave the distribution parameters of the random variable model used to simulate the start time of the steel corrosion unit in Table 3.

This paper only considers the corrosion of piers in the splash zone. The corrosion initiation time $T_{\text {init }}$ is calculated by Latin hypercube sampling (100000 samples), in which the random parameters of corrosion initiation time are shown in Table 3, and the concrete cover thicknesses are $40 \mathrm{~mm}$, $50 \mathrm{~mm}$, and $60 \mathrm{~mm}$, respectively. Figure 7 shows the frequency distribution histogram of corrosion initiation time and the fitted lognormal distribution under different cover thicknesses.

3.1.2. Current Density of Reinforcement Corrosion. Vu and Stewart [16] proposed the empirical formula of corrosion current density changing with time:

$$
\begin{aligned}
& i_{\text {corr }, 1}(t)=\frac{37.8(1-W / C)^{-1.64}}{c}, \quad t \leq T_{\text {init }}+1, \\
& i_{\text {corr }, 2}(t)=0.85 i_{\text {corr }, 1}\left(t-T_{\text {init }}\right)^{-0.29}, \quad T_{\text {init }}+1<t,
\end{aligned}
$$

where $W / C$ is the water-to-cement ratio, $c$ is the thickness of concrete cover $(\mathrm{cm}), i_{\text {corr }, 1}$ is the current density within one year from the beginning of corrosion $\left(\mu \mathrm{A} / \mathrm{cm}^{2}\right)$, and $i_{\text {corr }, 2}$ is the current density one year after the beginning of corrosion $\left(\mu \mathrm{A} / \mathrm{cm}^{2}\right)$.

In order to obtain the relationship between corrosion duration, water-to-cement ratio, and corrosion current density, firstly, the thickness of the concrete cover is assumed to be $50 \mathrm{~mm}$, and then the corrosion duration and water-to-cement ratio are randomly sampled (100000 samples). Finally, the corrosion current density is calculated by equations (2) and (3). The results are shown in Figure 8 .

3.2. Corrosion Rate of Reinforcement after Corrosion Expansion Cracking of Cover. The theoretical analysis model of $\mathrm{Lu}$ et al. [17] does not consider the corrosion expansion cracking time of the cover when the corrosion products enter the internal cracks of concrete and the time required for the steel corrosion products to fill the internal cracks of concrete and the model formula are as follows: 

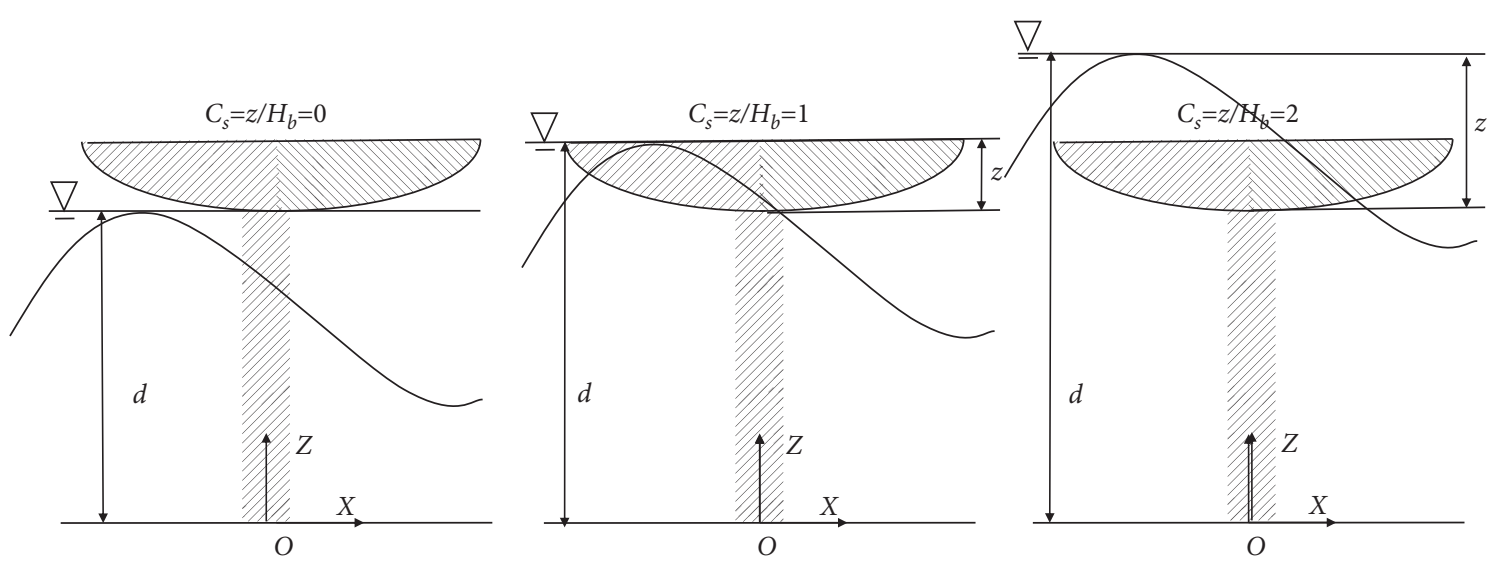

Figure 3: Diagram of impact submergence coefficient.
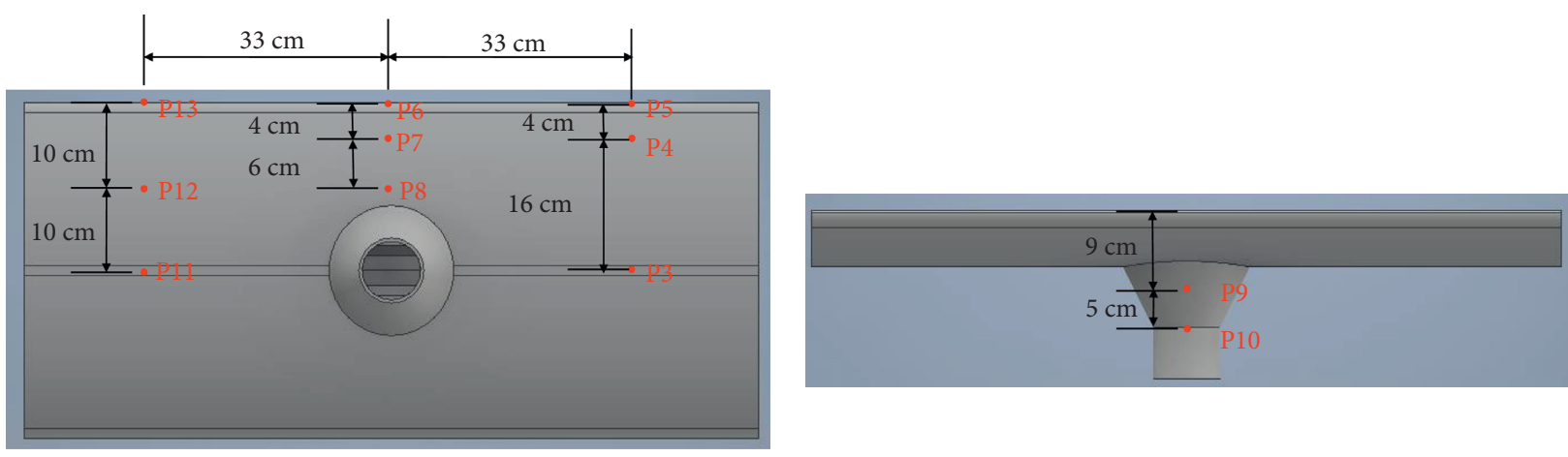

FiguRE 4: Diagram of pressure sensor placement.

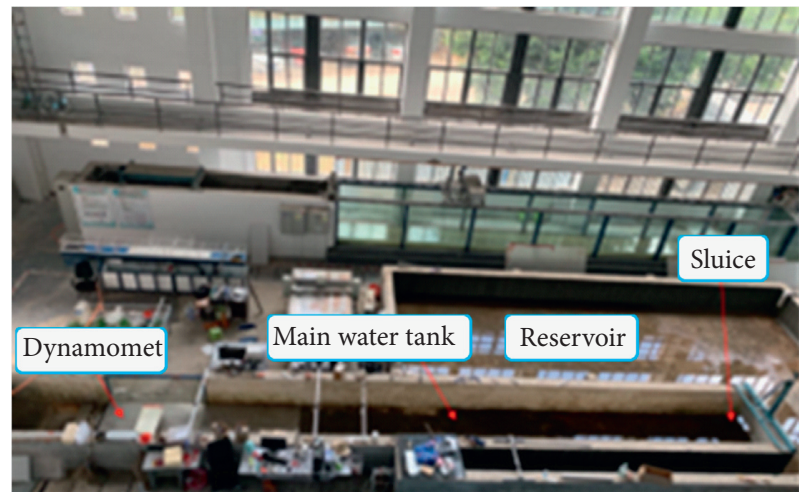

Figure 5: Diagram of the test tank.

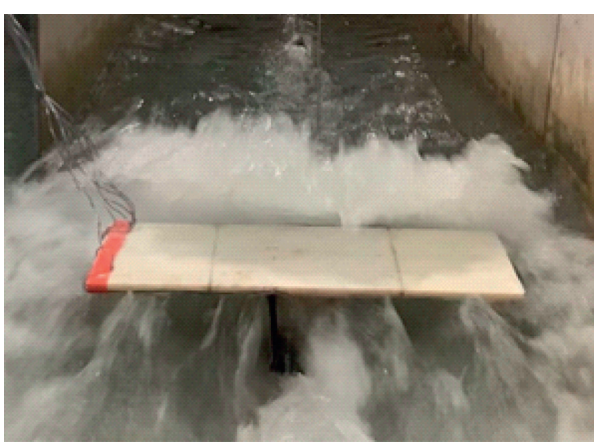

FIgURE 6: Tsunami impact test diagram.

$$
\begin{aligned}
t_{\mathrm{cr}}= & t_{1}+t_{2}=234762(d+k c) \\
& \times \frac{\left\{(0.3+0.6(c / d))\left(f_{t} / E_{\text {eff }}\right)\left[\left(\left(r_{0}+c\right)^{2}+r_{0}^{2} /\left(r_{0}+c\right)^{2}-r_{0}^{2}\right)+v_{c}\right]+1+\left(2 \delta_{0} / d\right)\right\}^{2}-1}{(n-1) i_{\text {corr }}}, \\
t_{2}= & k \frac{c}{d} t_{1},
\end{aligned}
$$

where $t_{1}$ is the cracking time $(h)$ of the cover without considering the corrosion products entering the cracks, $t_{2}$ is the time $(h)$ of the reinforcement corrosion products filling the internal cracks of the concrete, $k$ is a constant, $0.8 \sim 1.0$ is taken for long-term natural corrosion, $E_{\text {eff }}$ is the effective elastic modulus $(\mathrm{GPa})$ of the concrete, $v_{c}$ is Poisson's ratio of 
TABLE 1: The test results of tsunami wave parameters.

\begin{tabular}{|c|c|c|c|c|}
\hline No. & $W(\mathrm{~m})$ & $G(\mathrm{~m})$ & $u(\mathrm{~m} / \mathrm{s})$ & $h(\mathrm{~m})$ \\
\hline 1 & 0.5 & 0.25 & 2.63 & 0.172 \\
\hline 2 & 0.5 & 0.30 & 2.79 & 0.190 \\
\hline 3 & 0.5 & 0.35 & 2.89 & 0.201 \\
\hline 4 & 0.5 & 0.40 & 2.95 & 0.213 \\
\hline 5 & 0.5 & 0.45 & 2.90 & 0.220 \\
\hline 6 & 0.6 & 0.25 & 2.89 & 0.180 \\
\hline 7 & 0.6 & 0.30 & 3.11 & 0.201 \\
\hline 8 & 0.6 & 0.35 & 3.08 & 0.214 \\
\hline 9 & 0.6 & 0.40 & 3.17 & 0.238 \\
\hline 10 & 0.6 & 0.45 & 3.20 & 0.252 \\
\hline 11 & 0.7 & 0.25 & 3.06 & 0.191 \\
\hline 12 & 0.7 & 0.30 & 3.24 & 0.229 \\
\hline 13 & 0.7 & 0.35 & 3.17 & 0.251 \\
\hline 14 & 0.7 & 0.40 & 3.24 & 0.271 \\
\hline 15 & 0.7 & 0.45 & 3.20 & 0.282 \\
\hline
\end{tabular}

TABLE 2: The similarity ratio of box girder prototype and model parameters.

\begin{tabular}{lcccc}
\hline & Wave height $(\mathrm{m})$ & Wave velocity $(\mathrm{m} / \mathrm{s})$ & Submerged coefficient $\left(C_{\mathrm{s}}\right)$ & Wave direction $\left({ }^{\circ}\right)$ \\
\hline Prototype & $3.75-7.84$ & $13-16$ & $0-2$ & 0 \\
Model & $0.15-0.28$ & $2.6-3.2$ & $0-2$ & 0 \\
\hline
\end{tabular}

the concrete, $\delta_{0}$ is the thickness of porous zone, with an

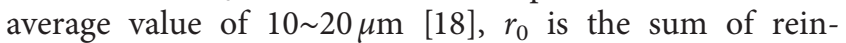
forcement radius and thickness of porous zone $(\mathrm{mm})$, and $n$ is the volume expansion rate of reinforcement corrosion products, taking $2.5 \sim 3.0$.

\subsection{Material Degradation Model of Corroded Reinforced} Concrete. It is assumed that the reinforcement is uniform corrosion, and the change of corrosion rate of reinforcement before and after expansion crack of cover is considered. Thus, the time-varying diameter of reinforcement can be expressed as follows:

$$
d(t)= \begin{cases}d_{0}-r_{1}\left(t-T_{\text {init }}\right), & T_{\text {init }}<t \leq T_{\alpha} \\ d_{0}-r_{1}\left(T_{\alpha}-T_{\text {init }}\right)-r_{2}\left(t-T_{\alpha}\right), & T_{\alpha}<t\end{cases}
$$

where $d(t)$ is the time-varying diameter of the reinforcement $(\mathrm{mm}), d_{0}$ is the initial diameter of the reinforcement $(\mathrm{mm}), T_{\text {init }}$ is the corrosion start time of the reinforcement (year), $T_{\mathrm{cr}}$ is the corrosion cracking time of the cover (year), $r_{1}$ is the radial corrosion rate of the reinforcement before the cover cracking ( $\mathrm{mm} /$ year), and the recommended value is $0.127 \mathrm{~mm} /$ year [19], and $r_{2}$ is the radial corrosion rate of the reinforcement after the cover cracking ( $\mathrm{mm} /$ year).

The cross section loss rate of reinforcement is expressed as a function of time.

$$
\rho(t)= \begin{cases}0, & t<T_{\text {init }}, \\ 1-\left(\frac{\mathrm{d}(t)}{\mathrm{d}_{0}}\right)^{2}, & T_{\text {init }}<t \leq T_{\text {init }}+\frac{d_{0}}{r}, \\ 1, & T_{\text {init }}+\frac{d_{0}}{r}<t,\end{cases}
$$

where $\rho(t)$ is the loss rate of steel section, $r$ is the radial corrosion rate of reinforcement ( $\mathrm{mm} /$ year), and $r_{1}$ or $r_{2}$ is selected according to different corrosion stages.

It should be noted that ABAQUS simulation adopts the degradation models of mechanical properties of corroded reinforcement and compressive strength of concrete proposed by Kashani et al. [20] and Coronelli and Gambarova [21], respectively.

\section{Numerical Simulation Model}

4.1. Background. ABAQUS finite element software [22] is used to analyze corroded piers with different service life $(0,10,20,30,40,50$ years $)$. Firstly, the whole bridge model is established. Then, the measured tsunami wave force is transformed into the finite element model of the whole bridge for structural dynamic analysis. Finally, through the pushover analysis of piers, the changes of bearing capacity and transverse stiffness of corroded piers before and after different tsunami wave conditions are compared. 
TABLE 3: Related parameters affecting $T_{\text {init }}$ random variables.

\begin{tabular}{lcccc}
\hline Parameter & Unit & Distribution type & Mean value & Coefficient of variation \\
\hline$C_{\text {crit }}$ & $\mathrm{kg} / \mathrm{m}^{3}$ & Uniform distribution & 0.9 & 0.19 \\
$C_{0}$ & $\mathrm{~kg} / \mathrm{m}^{3}$ & Lognormal distribution & 7.35 & 0.7 \\
$D_{\mathrm{c}}$ & $\mathrm{mm}^{2} / \mathrm{a}$ & Normal distribution & 161 & 1.42 \\
\hline
\end{tabular}

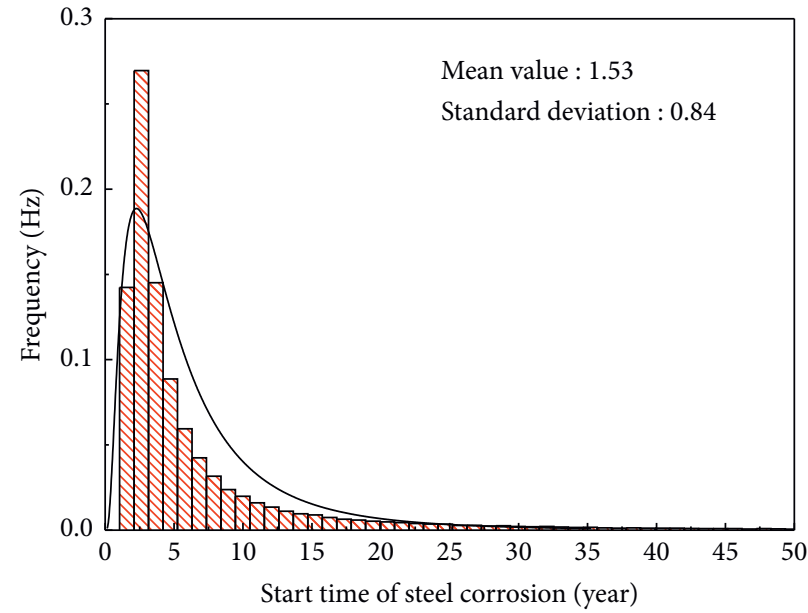

(a)

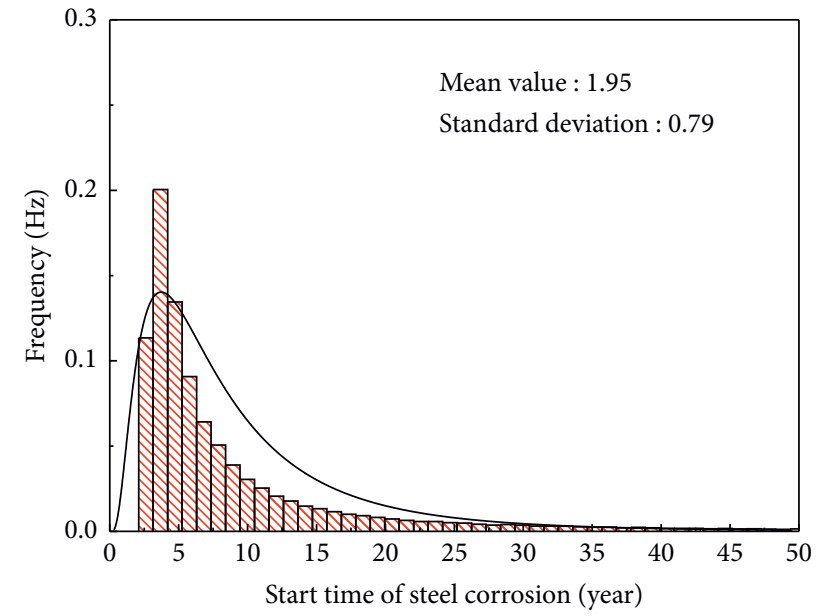

(b)

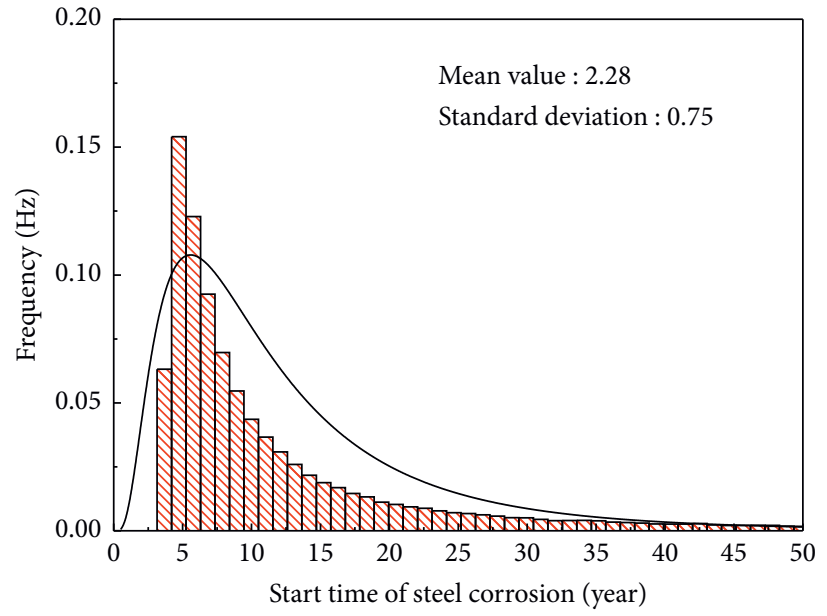

(c)

Figure 7: Frequency distribution histogram and fitting lognormal distribution of corrosion start time of steel bar under different cover thickness. (a) The thickness of concrete cover $c=40 \mathrm{~mm}$. (b) The thickness of concrete cover $c=50 \mathrm{~mm}$. (c) The thickness of concrete cover $c=60 \mathrm{~mm}$.

\subsection{Corroded Piers}

4.2.1. Layered Modeling of Corroded Piers. The pier simulation is mainly divided into three parts: cover concrete, core concrete, and steel bar. The pier height is $8 \mathrm{~m}$, the diameter is $1.6 \mathrm{~m}$, and the thickness of the cover concrete is $50 \mathrm{~mm}$. Since the constitutive model of the cover of the corroded pier is different from that of the core concrete material, it is necessary to establish the splash zone and the atmospheric zone when establishing the corrosion pier model, in which the height of the splash zone is $2 \mathrm{~m}$. In order to distinguish cover from core concrete, cover and core concrete define material properties independently. It needs to be explained that concrete adopts solid elements, and the element type is C3D8R; the Truss element is used in steel bar, and the element type is T3D2.

4.2.2. Constitutive Model of Corroded Concrete Materials. The concrete simulation of the pier is divided into cover concrete and core concrete, and C40 concrete is used. The damage plastic model of concrete is adopted as the constitutive model. The material parameters and damage factor calculation methods used in damage plastic modeling are all based on code for the design of concrete structures (GB 50010-2010) [23]. 


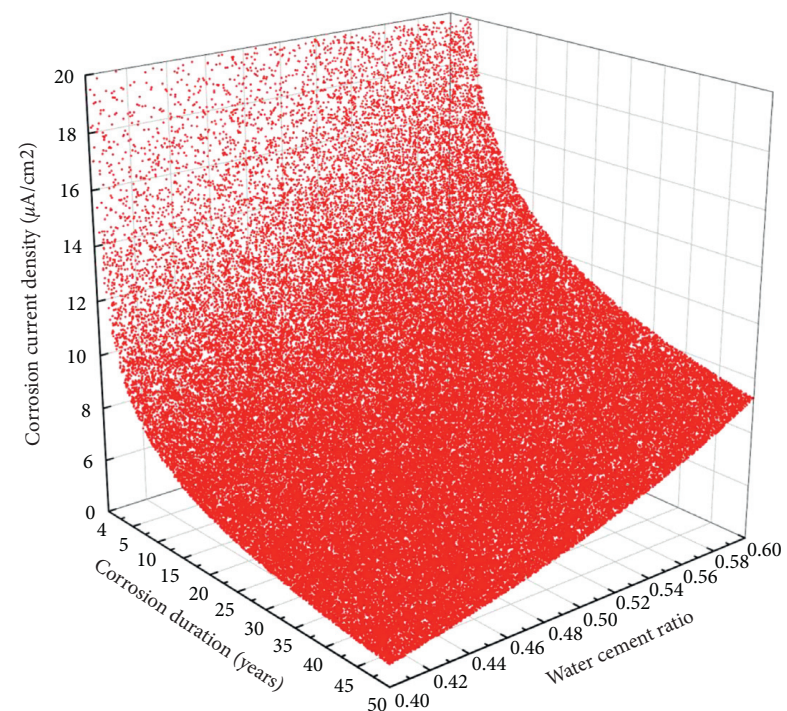

FIGURE 8: The scatter plot of the relationship between corrosion duration, water-to-cement ratio, and corrosion current density.

The degradation model of concrete compressive strength in splash zone adopts the degradation model introduced in Section 3. It should be noted that the compressive strength degradation of core concrete is not considered.

4.2.3. Properties of Corroded Steel Bar Materials. The longitudinal reinforcement and stirrup are $28 \mathrm{~mm}$ HRB400 and $16 \mathrm{~mm}$ HRB335, respectively. With the increase of service life, the steel bars will rust. There are two key time nodes here, i.e., the beginning time of steel corrosion in the splash zone of bridge pier $T_{\text {init }}$ and the corrosion expansion cracking time of cover $T_{\mathrm{cr}}$, which determine different steel corrosion rates. In Figure 7 of Section 3.1.1 the expected value of $T_{\text {init }}$ is 4 years after service when the thickness of $p$ cover is $50 \mathrm{~mm}$, and the calculated value is 4 years. The corrosion expansion cracking time $T_{\mathrm{cr}}$ is calculated by (4) of the corrosion expansion cracking time analysis model in Section 3.2, and the values of various parameters in the formula are shown in Table 4.

The corrosion current density $i_{\text {corr }}$ of the steel bar before corrosion expansion cracking is calculated by the integral value in Figure 8. When the water-to-cement ratio is 0.4 , the relationship between corrosion current density $i_{\text {corr }}$ and corrosion time is shown in Figure 9. Through equation (4), it can be obtained that $T_{\text {cr }}$ is 3.5 years after the beginning of corrosion, and the corrosion expansion cracking time $T_{\mathrm{cr}}$ is 7.5 years for the sake of conservation.

After determining the corrosion start time $T_{\text {init }}$ and corrosion expansion cracking time $T_{\mathrm{cr}}$ of pier steel bars in the splash zone, the time-varying diameter and section loss rate of steel bars under different service life are calculated by equations (6) and (7) in Section 3.3. The specific calculation results are shown in Table 5 .

It should be noted that the constitutive model required to define other material properties of reinforcement is the model described in Section 3.3.
4.3. Girder. The girder is a three-room reinforced concrete box girder with equal cross section, and C50 concrete is used (see Section 2.1 for the specific size). The girder is modeled by the solid element, and the element type is C3D8R. It should be noted that the girder is only used to bear the impact of waves and transfer the forces on the superstructure to the pier, and only the elastic stage of the beam is considered.

4.4. Pile Foundation. The simulated pile foundation is a circular single-column pile with a height of $41.5 \mathrm{~m}$ and a diameter of $2 \mathrm{~m}$. Pile foundation is modeled using C30 concrete and eight-node solid elements with reduced integration (C3D8R), and the reinforcement ratio and reinforcement mode of pile foundation are considered in the modeling.

The pile-soil interaction is equivalent by applying spring boundary conditions. The stratum of pile foundation is mainly the silt and sand soil layer. The clay material parameters are calculated according to the $p-y$ curve recommended by Matlock, and the sand material parameters can be calculated according to the $p-y$ curve recommended by the American API code. The relevant soil parameters required to define the spring boundary conditions are shown in Table 6.

4.5. Abutment. The abutment is a pile abutment. When the bridge is impacted by waves, the main effect of the abutment on the girder is the longitudinal and transverse restraint. Therefore, the equivalent constraint is established to simulate the abutment. Because the abutment and the girder are connected by rubber bearings, the abutment does not provide vertical restraint for the girder when it is impacted by waves, and the horizontal restraint mainly comes from the friction between the superstructure and the substructure. According to the research of Huang et al. [24], the friction coefficient of rubber bearing is 0.8 , and the friction resistance is obtained by multiplying the vertical force on the bearing by the friction coefficient. It should be noted that the vertical deformation of the abutment is not considered.

4.6. Collision. In the longitudinal direction of the bridge, the collision between the girder and the abutment will have a great impact on the dynamic analysis of the bridge. According to the experimental conclusion of Wang et al. [25], the stiffness of the impact element is defined as 0.5 times the axial stiffness of the girder.

4.7. Damping. Rayleigh damping is used to simulate the damping of the bridge, that is, the combination matrix represented by equation (8), including mass matrix and stiffness matrix.

$$
[C]=\alpha[M]+\beta[K],
$$

where $\alpha$ is the mass damping coefficient and $\beta$ is the stiffness damping coefficient. It should be noted that $\alpha$ and $\beta$ are 
TABle 4: Parameter values of $T_{\mathrm{cr}}$ model for corrosion expansion cracking time.

\begin{tabular}{lccccccccc}
\hline Parameter & $k$ & $d(\mathrm{~cm})$ & $c(\mathrm{~cm})$ & $f_{\mathrm{t}}(\mathrm{MPa})$ & $E_{\text {eff }}(\mathrm{GPa})$ & $r_{0}(\mathrm{~cm})$ & $n$ & $v_{c}$ & $\delta_{0}(\mathrm{~cm})$ \\
\hline Value & 0.9 & 1.6 & 5 & 2.4 & 32.5 & 0.8015 & 2.75 & 0.2 & 0.0015 \\
\hline
\end{tabular}

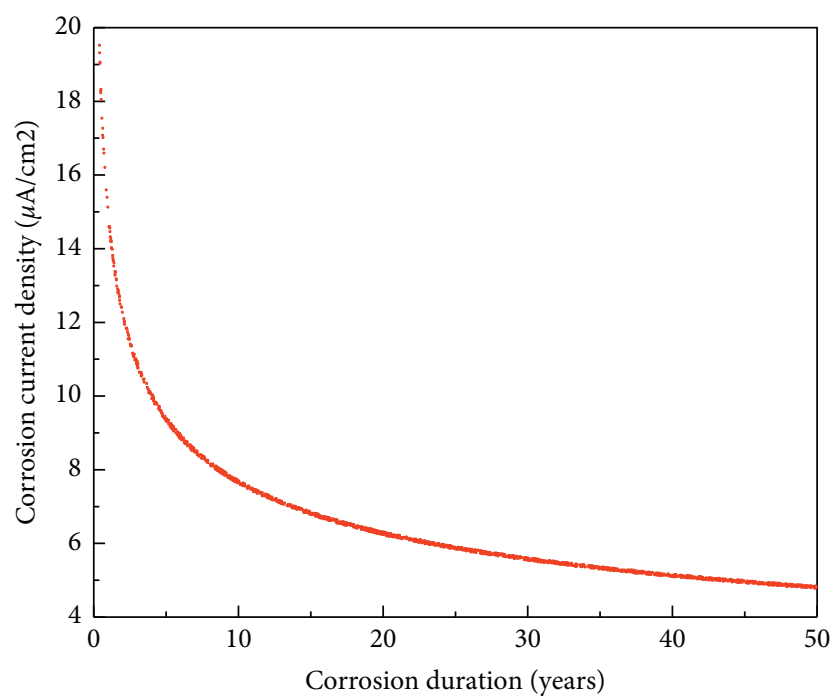

FIgURE 9: Relationship between corrosion current density and corrosion duration before corrosion expansion cracking.

Table 5: Time-varying diameter and section loss rate of pier reinforcement in splash area under different service life.

\begin{tabular}{lccccccc}
\hline & Service life (years) & 0 & 10 & 20 & 30 & 40 & 50 \\
\hline \multirow{2}{*}{ Longitudinal bar } & Diameter $(\mathrm{mm})$ & 28 & 26.60 & 25.97 & 24.84 & 23.46 \\
& Section loss rate (\%) & 0 & 9.75 & 13.97 & 21.30 & 29.80 & 40.43 \\
\hline \multirow{2}{*}{ Stirrup } & Diameter (mm) & 16 & 14.6 & 13.97 & 12.84 & 11.46 \\
& Section loss rate (\%) & 0 & 16.73 & 23.76 & 35.60 & 48.70 & 63.91 \\
\hline
\end{tabular}

obtained by modal damping, and the modal damping ratio of concrete structures is set as 0.05 .

In summary, the established ABAQUS full-bridge model is shown in Figure 10.

4.8. Wave Force. According to the ratio of the test model, wave condition, and the Froude similarity criterion, the wave force on the impacted side of the girder is distributed in the form of pressure. By assuming that the wave impact pressure on the surface of the girder at the same horizontal height is equal and the corresponding pressure force area is divided at the sensor point, the pressure measured by the test is extended to the whole surface of the girder, and the hydrostatic pressure varying with water depth is applied to the surface of the unimpacted side of the girder to simulate the buoyancy of the girder. The wave force on the pier is added to the surface of the pier under impact in the form of surface load. The resultant force is obtained by reducing the horizontal force measured by the test and subtracting the horizontal force on the girder. The buoyancy on the pier is simulated by the hydrostatic pressure changing with the water depth. The loading time of wave force is enlarged by five times according to the similarity criterion; that is, the action time is $30 \mathrm{~s}$. The simulation of wave force is shown in Figure 11.
TABLE 6: Relevant soil parameters.

\begin{tabular}{lcc}
\hline Underground depth & Soil type & $p_{\text {ult }}(\mathrm{kN} / \mathrm{m})$ \\
\hline $0 \sim 5 \mathrm{~m}$ underground & Silt & 308 \\
$5 \sim 10 \mathrm{~m}$ underground & Sand & 6075 \\
$10 \sim 15 \mathrm{~m}$ underground & Sand & 10125 \\
$15 \sim 20 \mathrm{~m}$ underground & Sand & 14175 \\
$20 \sim 25 \mathrm{~m}$ underground & Sand & 18225 \\
$25 \sim 30 \mathrm{~m}$ underground & Sand & 22275 \\
$30 \sim 35 \mathrm{~m}$ underground & Sand & 26325 \\
$35 \sim 41.5 \mathrm{~m}$ underground & Sand & 30983 \\
\hline
\end{tabular}

Note. Limit soil resistance for $p-y$ material in the current loading direction.

\section{Results and Discussion}

5.1. Dynamic Response Analysis of Piers under Different Tsunami Wave Conditions. According to the 100-year high water level and wave conditions in the sea area of the bridge site, six groups of tsunami wave conditions in the test results are selected and converted through the similarity criteria of the hydrodynamic test. The converted tsunami wave parameters are shown in Table 7 . The tsunami wave force corresponding to the above tsunami wave conditions is 


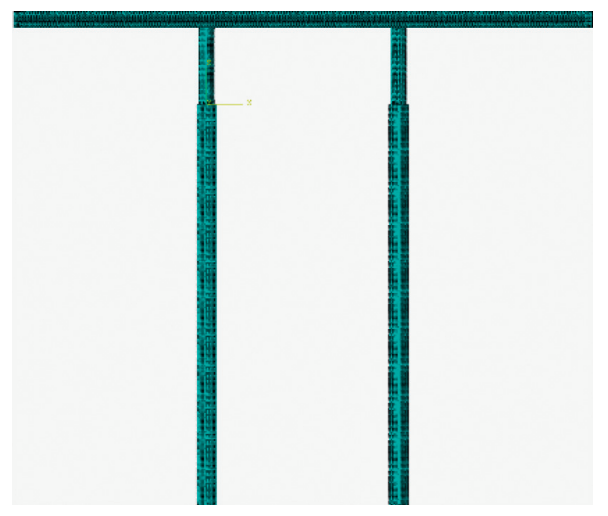

(a)

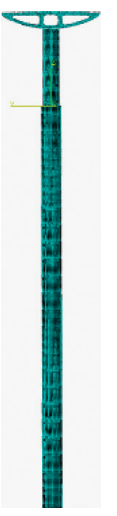

(b)

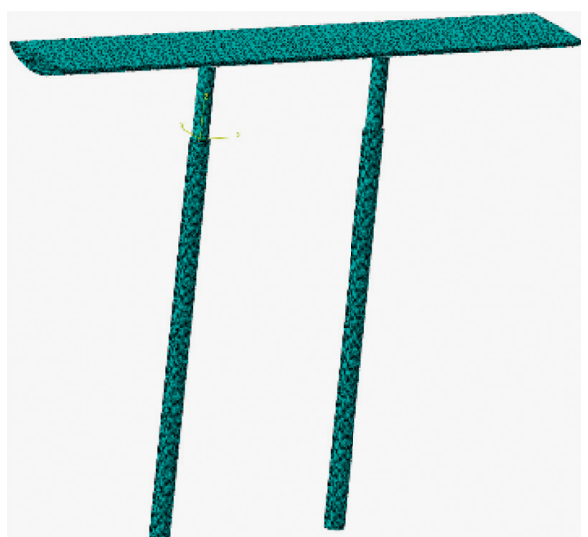

(c)

FIgURE 10: Diagram of ABAQUS full-bridge model.

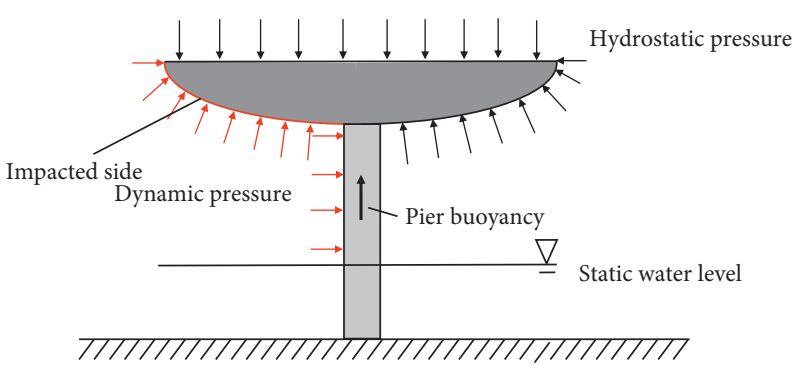

FigURE 11: Diagram of wave force simulation.

loaded on the whole bridge model to obtain the dynamic response of the pier bottom under different tsunami wave conditions.

\subsubsection{Time History Analysis of Shear Force at Pier Bottom} under Tsunami Wave. By loading the tsunami wave force corresponding to HXB-1 HXB- 6 in Table 7 on the (noncorrosion) full-bridge model, the time history curve of pier bottom shear force is obtained as shown in Figure 12. It should be noted that the degrees of freedom of incident wave direction, vertical direction, and longitudinal rotation around the bridge are only considered in wave loading.

The pier bottom shear force is mainly caused by the horizontal component of wave force. From the time history curve of shear force of pier bottom, it can be seen that when the tsunami wave impacts the bridge, with the change of time, firstly, the pier bottom shear force will reach the peak value instantly, which is the attack force of the tsunami wave, and then the shear force will decrease considerably and increase slowly with the increase of wave height. Finally, the shear will decrease slowly, which is consistent with the wave force trend obtained from the test. In addition, when the wave impact coefficient is less than 2 , as shown in Figures 12(a) and 12(d), it can be seen that the peak shear force of the pier increases with the increase of the impact submergence coefficient and wave velocity. When the impact submergence coefficient is greater than or equal to 2 , as
TABle 7: Converted tsunami wave parameters.

\begin{tabular}{lcccc}
\hline $\begin{array}{l}\text { Tsunami } \\
\text { wave } \\
\text { number }\end{array}$ & $\begin{array}{c}\text { Wave } \\
\text { velocity } u \\
(\mathrm{~m} / \mathrm{s})\end{array}$ & $\begin{array}{c}\text { Wave } \\
\text { height } \\
h(\mathrm{~m})\end{array}$ & $\begin{array}{c}\text { Submergence } \\
\text { coefficient } C_{\mathrm{s}}\end{array}$ & $\begin{array}{c}\text { Water } \\
\text { level } \\
\text { height } H \\
(\mathrm{~m})\end{array}$ \\
\hline HXB-1 & 5.88 & 4.300 & 0.60 & 4.75 \\
HXB-2 & 6.46 & 5.025 & 1.01 & 4.75 \\
HXB-3 & 6.95 & 5.025 & 1.01 & 4.75 \\
HXB-4 & 7.25 & 5.725 & 1.41 & 4.75 \\
HXB-5 & 7.25 & 6.775 & 2.01 & 4.75 \\
HXB-6 & 7.25 & 7.050 & 2.17 & 4.75 \\
\hline
\end{tabular}

shown in Figures 12(e) and 12(f), the wave velocities of the two kinds of tsunamis are the same, and the impact submergence coefficients are 2.01 and 2.17, respectively. There is no obvious difference in the peak shear force at the bottom of the pier after the action of the two kinds of tsunamis. Therefore, it can be judged that the relationship between the horizontal component of wave force and the impact submergence coefficient does not belong to monotonic increasing.

5.1.2. Time History Analysis of Moment at Pier Bottom under Tsunami Wave. By loading the tsunami wave forces corresponding to HXB-1 HXB-6 in Table 7 on the (noncorrosive) finite element full-bridge model, the moment time history curve of pier bottom is obtained as shown in Figure 13. 


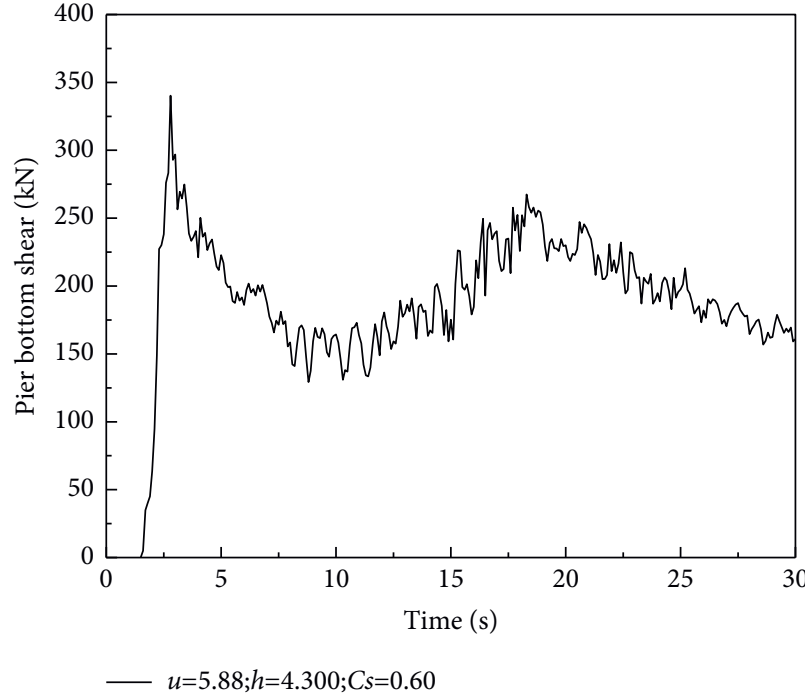

(a)

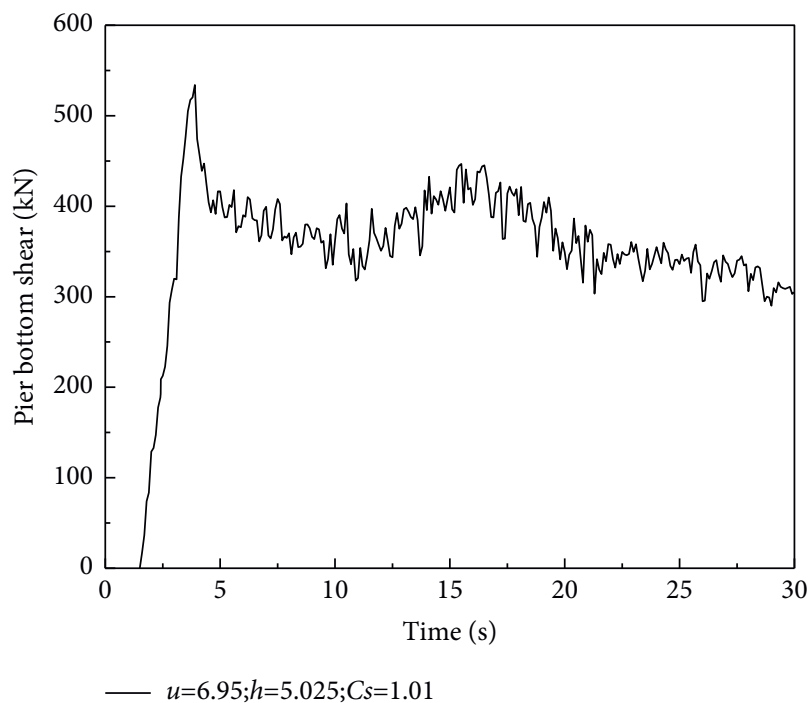

(c)

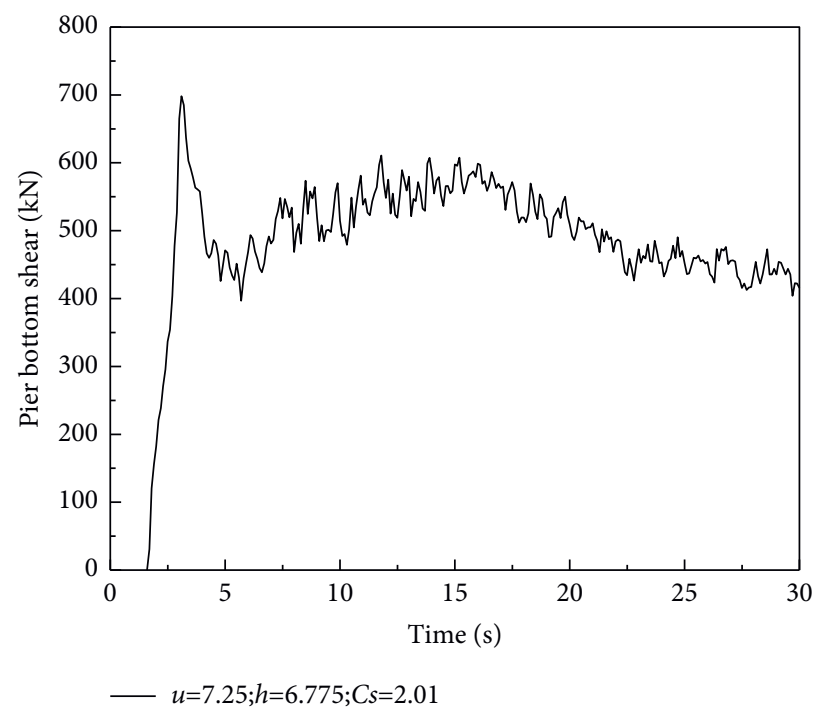

(e)

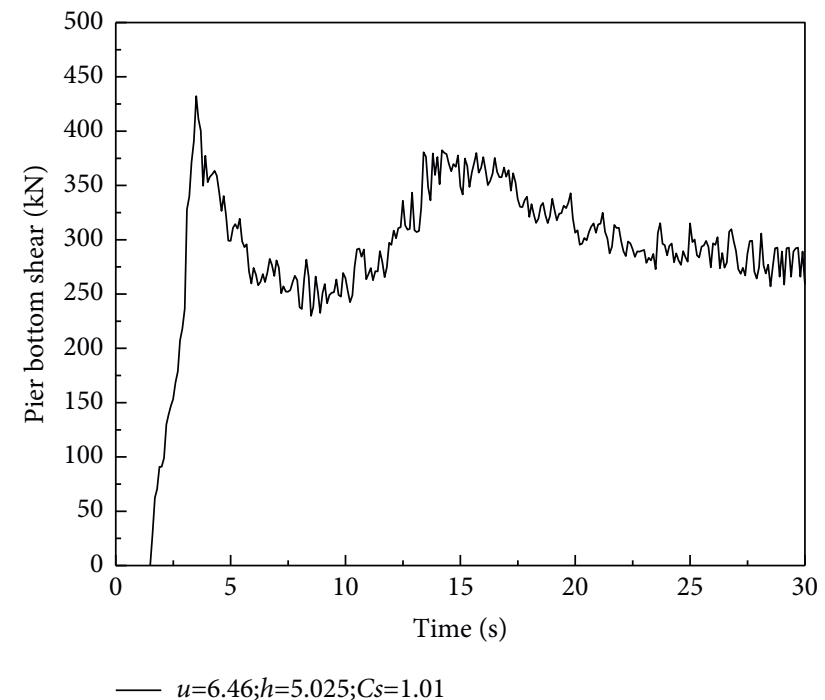

(b)

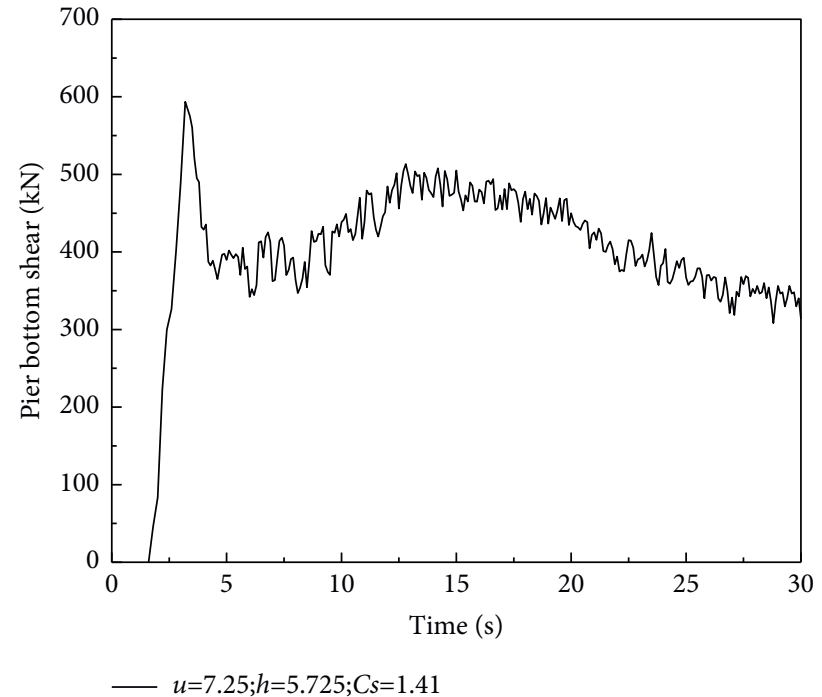

(d)

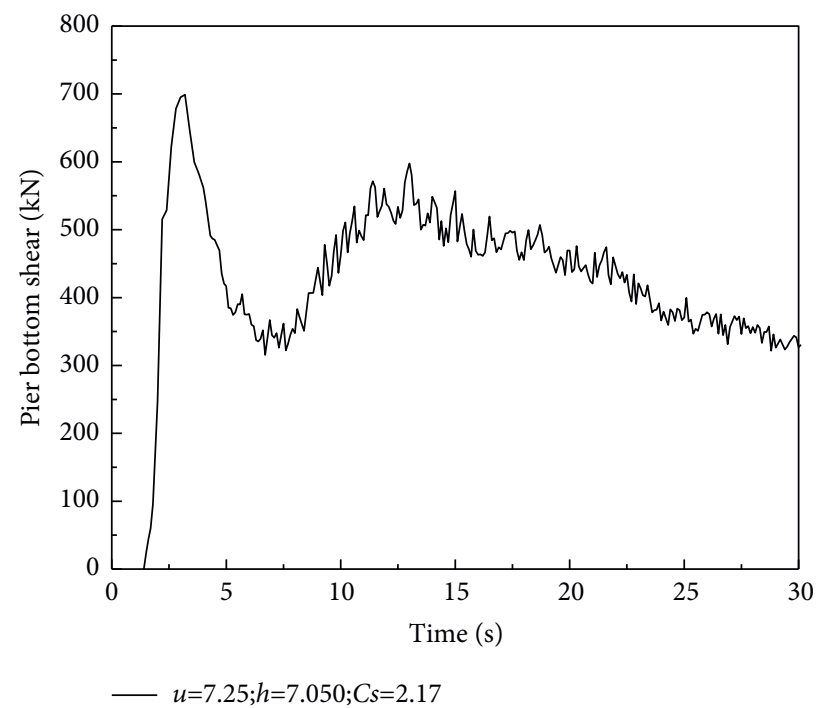

(f)

FIGURE 12: Time history curve of pier bottom shear force under different tsunami wave conditions. Time history curve of shear force acting on pier bottom of (a) HXB-1, (b) HXB-2, (c) HXB-3, (d) HXB-4, (e) HXB-5, and (f) HXB-6. 

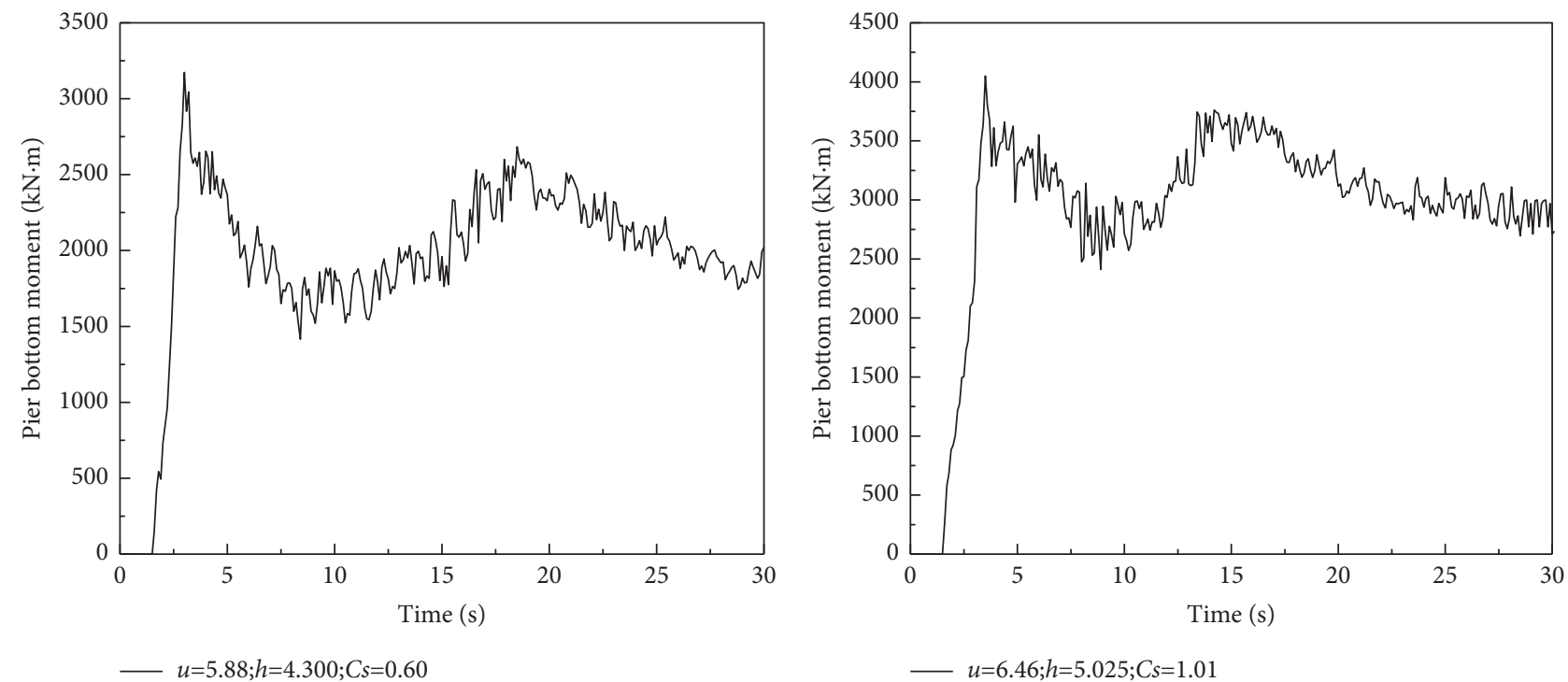

(a)
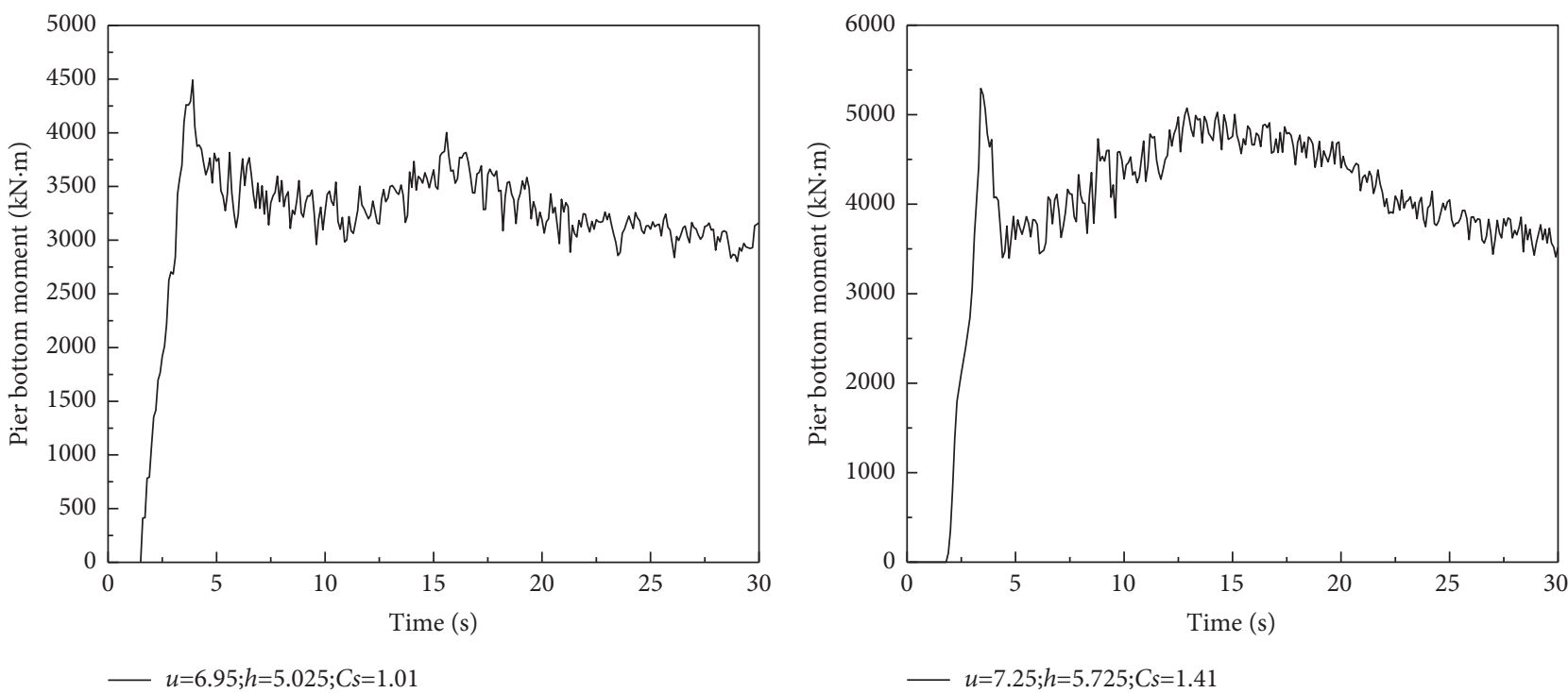

(c)

(d)

Figure 13: Continued. 


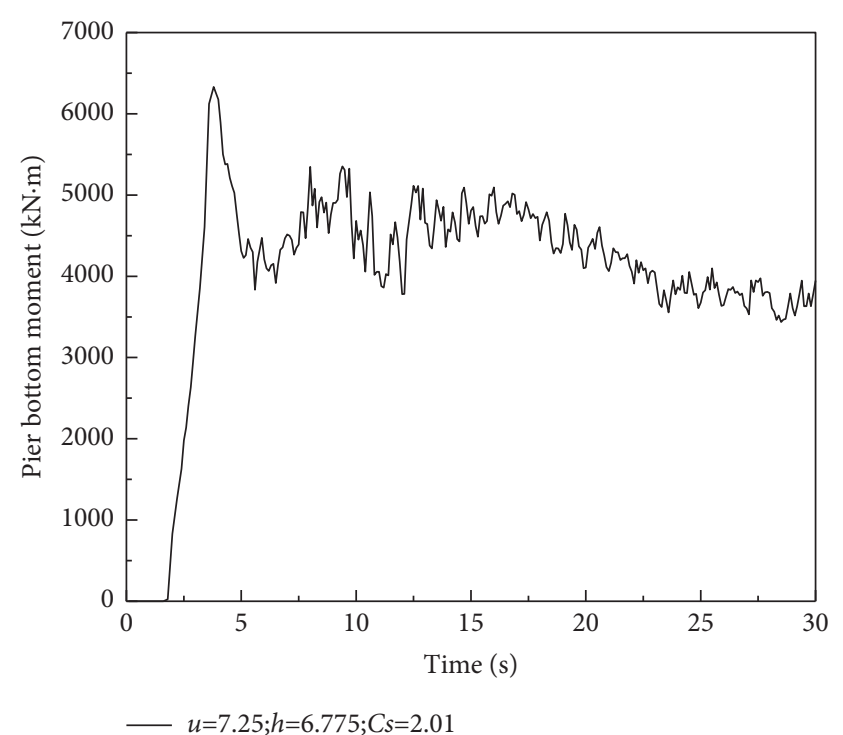

(e)

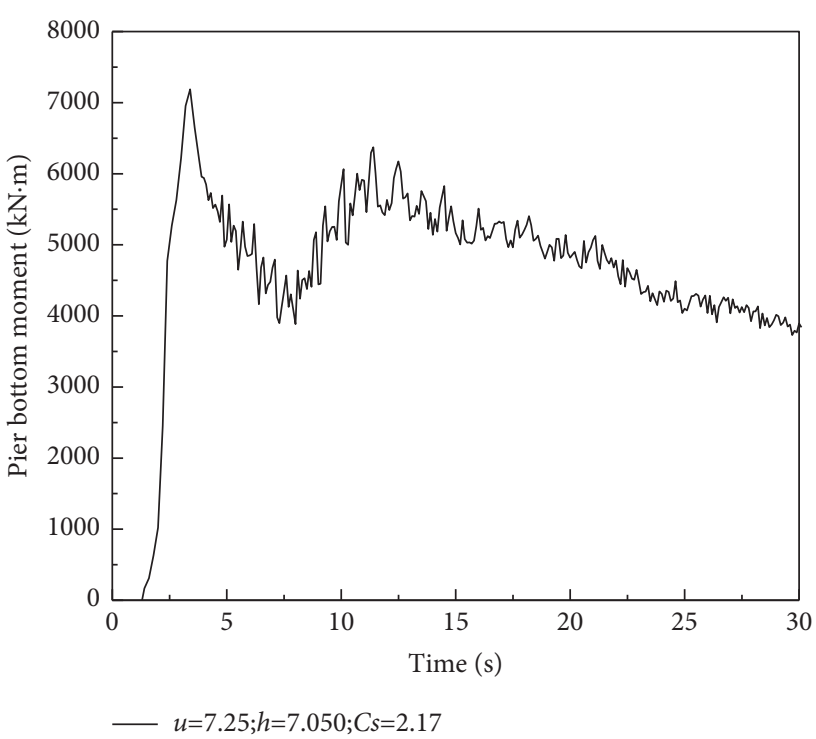

(f)

Figure 13: Time history curve of the moment at pier bottom under different tsunami wave conditions. Time history curve of the moment at pier bottom under (a) HXB-1 action, (b) HXB-2 action, (c) HXB-3 action, (d) HXB-4 action, (e) HXB-5 action, and (f) HXB-6 action.

The pier bottom moment is caused by the combined action of horizontal and vertical components of wave force. From the moment time history curve of pier bottom, it can be seen that when the tsunami wave impacts the bridge, with the change of time, firstly, the pier bottom moment will reach the peak value instantly, which is the attack force of tsunami wave, then the moment will have a significant decrease, and the moment will decrease considerably and increase slowly with the increase of wave height. Finally, the moment will decrease slowly, which is consistent with the changing trend of the pier bottom shear time history curve. In addition, for HXB-2 and HXB-3, the impact submergence coefficients of the two kinds of tsunami waves are the same, and the wave velocities are $6.46 \mathrm{~m} / \mathrm{s}$ and $6.95 \mathrm{~m} / \mathrm{s}$, respectively. The peak shear force at the bottom of the pier is $431 \mathrm{kN}$ and $535 \mathrm{kN}$, respectively, and the peak moment at the bottom of the pier is $4058 \mathrm{kN} \cdot \mathrm{m}$ and $4507 \mathrm{kN} \cdot \mathrm{m}$, respectively. It can be seen that when the wave velocity increases by $7.6 \%$, the peak shear force and moment at the pier bottom increase by $24.1 \%$ and $11.1 \%$, respectively. Compared with the vertical force, the influence of wave velocity on the horizontal component of wave force is more remarkable.

It is worth noting that when the impact submergence coefficient is greater than 2, as shown in Figures 13(e) and 13(f), the wave velocities of the two tsunami waves are the same, and the impact submergence coefficients are 2.01 and 2.17 , respectively, which are significantly different from the pier bottom shear, and the pier bottom moment is still significantly increased. It is proved that, under this condition, the horizontal component of the wave force does not increase significantly, and the vertical component of the wave force increases greatly, and the vertical component of the wave force has a larger impact on the pier bottom moment.
5.2. Seismic Performance of Corroded Pier under Wave Action. In order to study the seismic performance of corroded piers under wave action, wave conditions HXB-3, HXB-4, and HXB-5 are firstly selected and loaded on the full-bridge models with the service life of $0,10,20,30,40$, and 50 years, respectively. After the wave impact is completed, the damage caused by wave impact can be recorded and retained by the damaged plastic model of concrete used in bridge piers. Then, the analysis step is created to carry out the pushover analysis on piers, and the bearing capacity of bridge piers with different service life under different tsunami wave conditions is obtained. Finally, the changes of transverse/ vertical bearing capacity and transverse stiffness of piers under the simultaneous action of wave impact and chloride ion corrosion are analyzed.

5.2.1. Failure Mode of the Pier under Wave Impact. The finite element simulation results show that the concrete in the compression zone is completely damaged, and the shear deformation at the bottom of the pier is far less than the bending deformation. According to the bending-bendingshear-shear failure criterion proposed by Sun et al. [26] (shear deformation/bending deformation $<0.2$ ), it is judged that the failure mode of the pier is bending failure when the tsunami wave impacts the bridge structure.

5.2.2. Bearing Capacity Analysis of Corroded Bridge Piers before and after Wave Impact. The lateral and longitudinal pushover analysis of the pier is carried out by displacement control. Firstly, the lateral displacement of the pier top is 0 , $0.05,0.1,0.15$, and $0.2 \mathrm{~m}$ to obtain the lateral bearing capacity and stiffness of the corroded pier after wave impact. Then, the vertical displacement on the top of the pier is $-0,-0.01$, $-0.02,-0.03,-0.04$, and $-0.05 \mathrm{~m}$, and the vertical bearing 


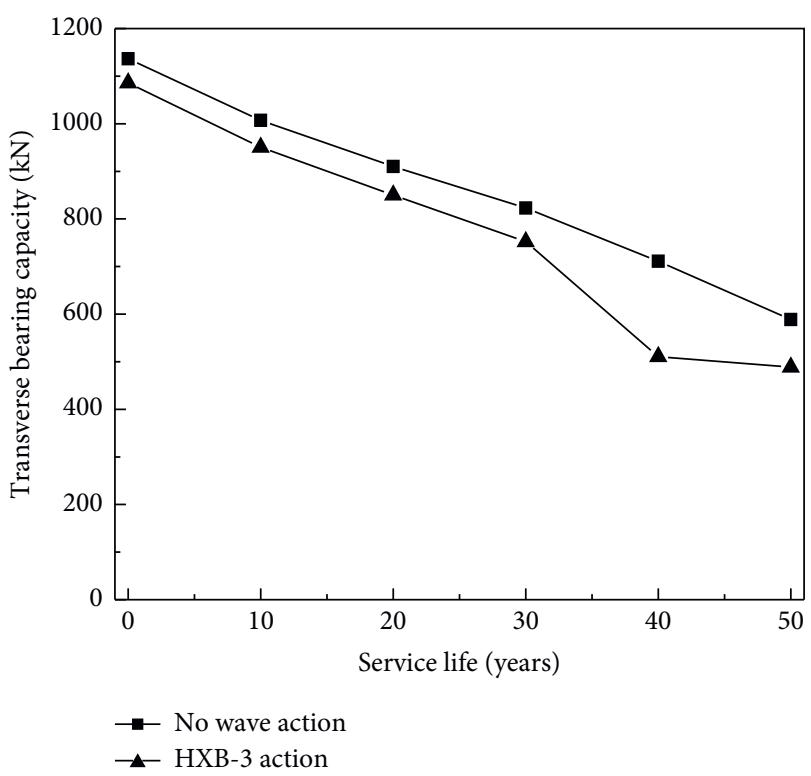

(a)

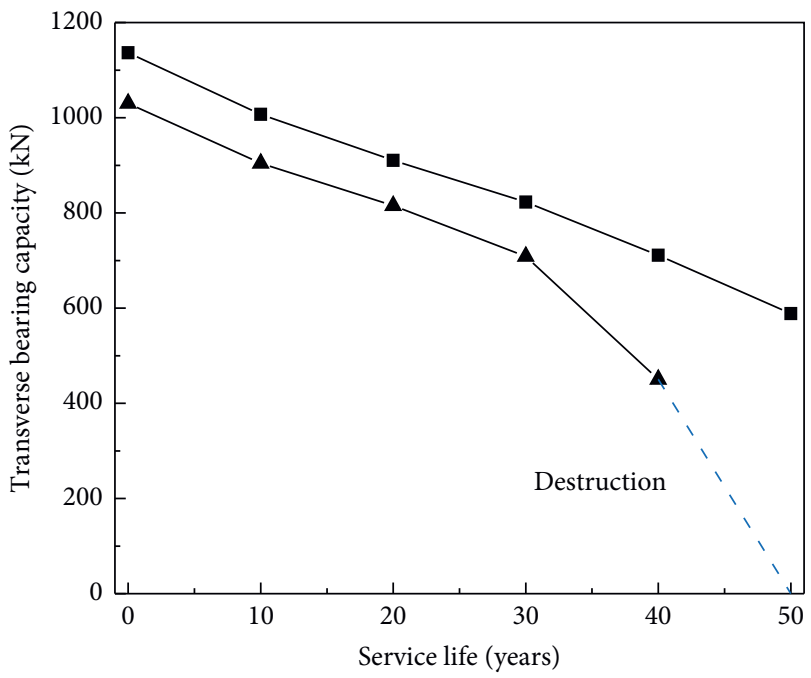

$\rightarrow$ No wave action

$\neg$ HXB-4 action

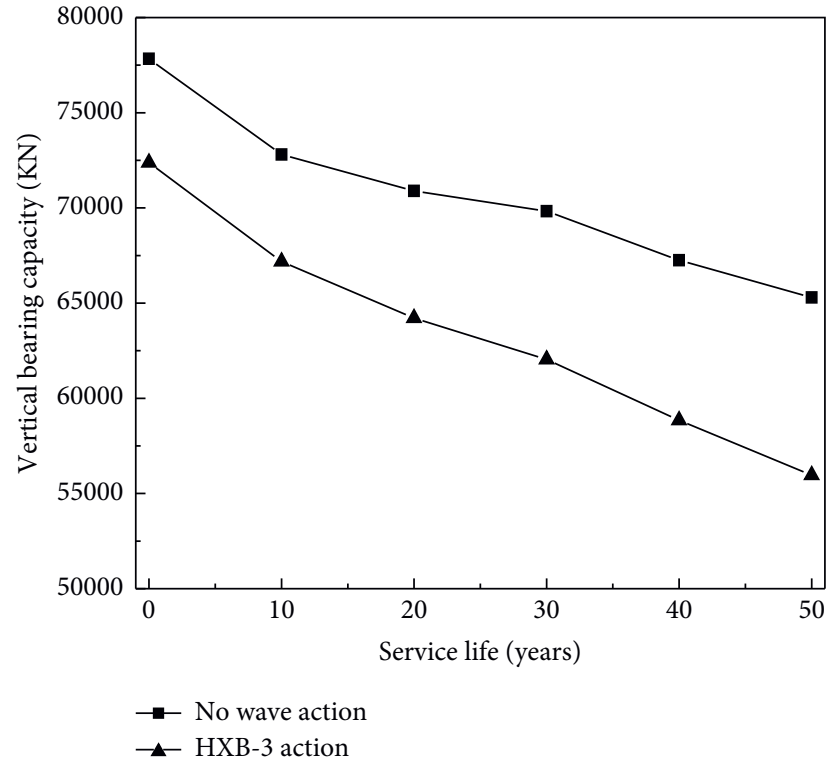

(b)

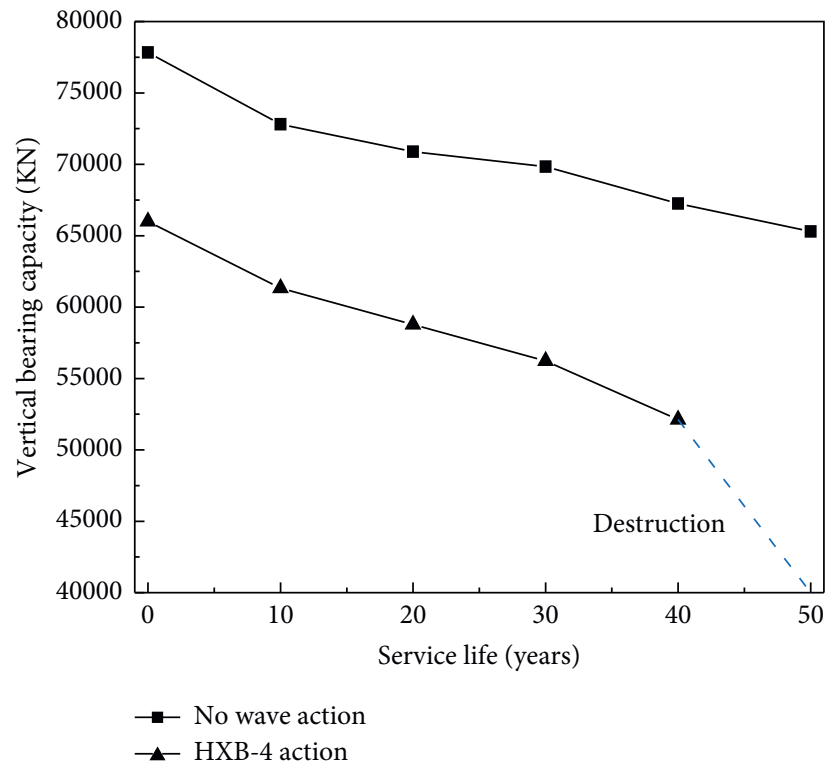

(d)

Figure 14: Continued. 


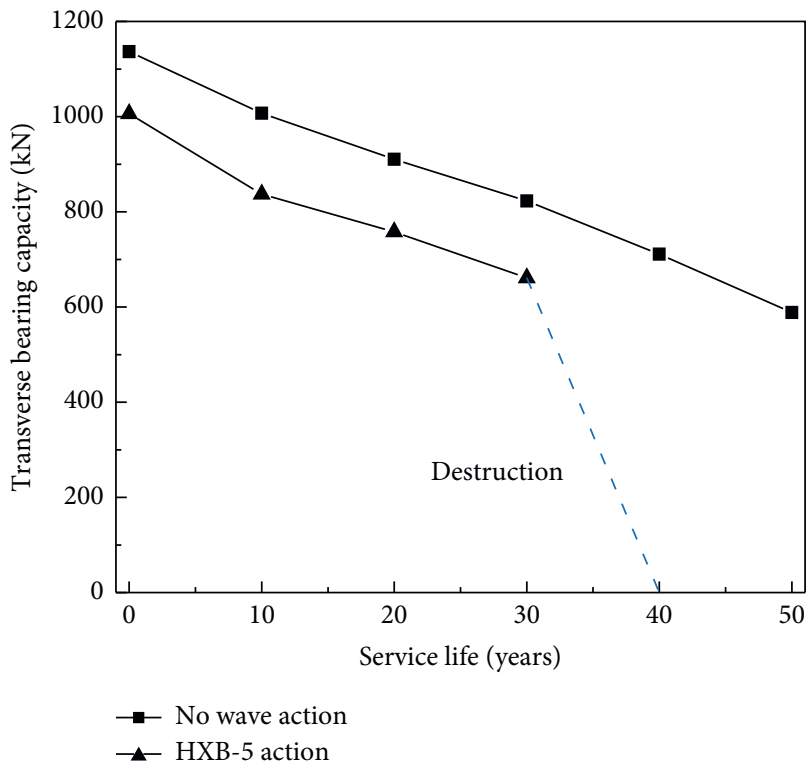

(e)

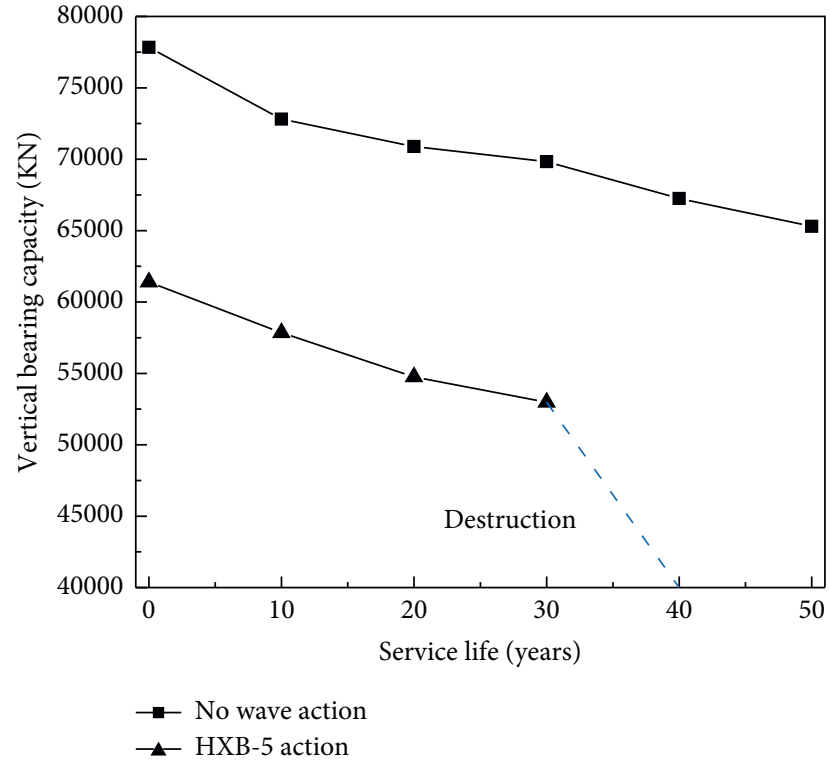

(f)

FIGURE 14: Comparison of bearing capacity of piers with different service life under different conditions of tsunami wave. (a) Lateral bearing capacity of pier after HXB-3 action. (b) Vertical bearing capacity of pier after HXB-3 action. (c) Lateral bearing capacity of pier after HXB-4 action. (d) Vertical bearing capacity of pier after HXB-4 action. (e) Lateral bearing capacity of the pier after HXB-5 action. (f) Vertical bearing capacity of the pier after HXB-5 action.

TABLE 8: Comparison of bearing capacity of corroded piers under different tsunami waves.

\begin{tabular}{|c|c|c|c|c|c|c|c|}
\hline Bearing capacity $(\mathrm{kN})$ & Wave condition & 0 years & 10 years & 20 years & 30 years & 40 years & 50 years \\
\hline \multirow{7}{*}{ Transverse } & \multirow{2}{*}{ No wave } & 1136 & 1007 & 910 & 823 & 711 & 589 \\
\hline & & $0 \%$ & $-11.4 \%$ & $-19.9 \%$ & $-27.6 \%$ & $-37.4 \%$ & $-48.2 \%$ \\
\hline & \multirow{2}{*}{ HXB-3 } & 1086 & 951 & 850 & 752 & 511 & 488 \\
\hline & & $-4.5 \%$ & $-16.4 \%$ & $-25.2 \%$ & $-33.8 \%$ & $-55.0 \%$ & $-57.0 \%$ \\
\hline & \multirow{2}{*}{ HXB-4 } & 1030 & 904 & 815 & 709 & 450 & \multirow{2}{*}{ Destruction } \\
\hline & & $-9.3 \%$ & $-20.4 \%$ & $-28.3 \%$ & $-37.7 \%$ & $-60.4 \%$ & \\
\hline & HXB-5 & $\begin{array}{c}1006.28 \\
-11.45 \%\end{array}$ & $\begin{array}{c}837 \\
-26.3 \%\end{array}$ & $\begin{array}{c}758 \\
-33.3 \%\end{array}$ & $\begin{array}{c}661 \\
-41.8 \%\end{array}$ & Destruction & Destruction \\
\hline \multirow{7}{*}{ Vertical } & \multirow{2}{*}{ No wave } & 77832 & 72806 & 70890 & 69832 & 67250 & 65298 \\
\hline & & $0 \%$ & $-6.5 \%$ & $-8.9 \%$ & $-10.3 \%$ & $-13.6 \%$ & $-16.1 \%$ \\
\hline & \multirow{2}{*}{ HXB-3 } & 72377 & 67183 & 64216 & 62036 & 58845 & 55959 \\
\hline & & $-7.0 \%$ & $-13.7 \%$ & $-17.5 \%$ & $-20.3 \%$ & $-24.4 \%$ & $-28.1 \%$ \\
\hline & \multirow{2}{*}{ HXB-4 } & 65993 & 61327 & 58781 & 56232 & 52123 & \multirow{2}{*}{ Destruction } \\
\hline & & $-15.2 \%$ & $-21.2 \%$ & $-24.5 \%$ & $-27.8 \%$ & $-33.0 \%$ & \\
\hline & HXB-5 & $\begin{array}{c}61403 \\
-21.1 \%\end{array}$ & $\begin{array}{c}57848 \\
-25.7 \%\end{array}$ & $\begin{array}{c}54759 \\
-29.6 \%\end{array}$ & $\begin{array}{c}52981 \\
-31.9 \%\end{array}$ & Destruction & Destruction \\
\hline
\end{tabular}

Note. The ratio is the value of bearing capacity of damaged pier compared with that of the undamaged pier.

capacity of the corroded pier after wave impact is obtained. Finally, the lateral and vertical bearing capacities of piers with different service life are shown in Figure 14 and Table 8. It should be noted that, in order to make the damage on the compression side of the pier, the direction of lateral overturning is consistent with that of wave impact.

As shown in Figure 14 and Table 8, these results are as follows:
(1) In the absence of wave action, the lateral bearing capacity and vertical bearing capacity decrease by $48.2 \%$ and $16.1 \%$, respectively, from 0 to 50 years. Therefore, it is indispensable to consider the corrosion environment of piers when evaluating offshore bridges. In addition, compared with the transverse bearing capacity, the vertical bearing capacity of the pier has a lower decline rate in 


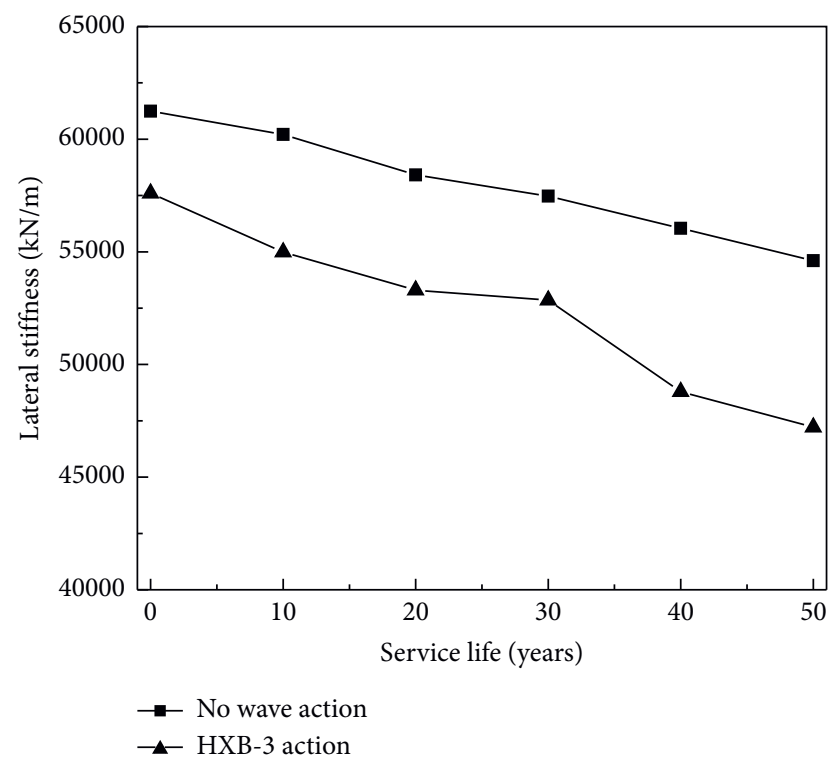

(a)

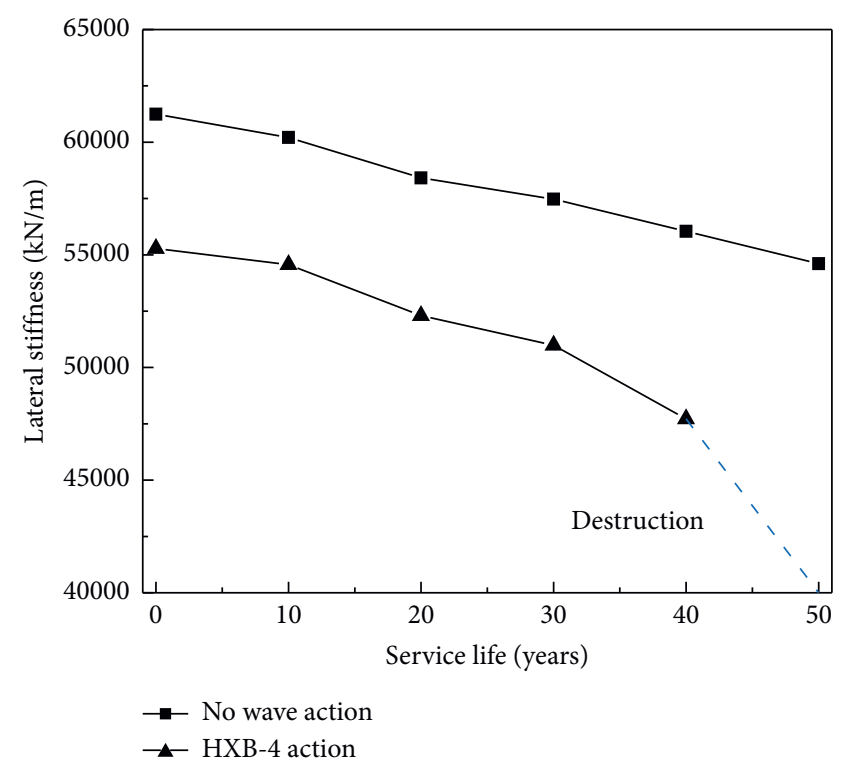

(b)

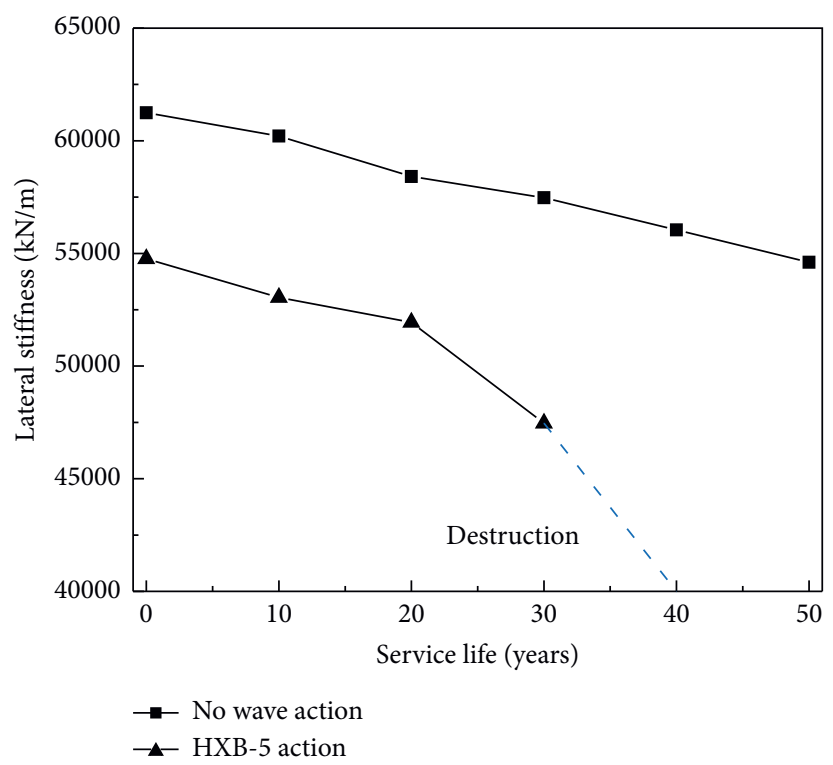

(c)

FiguRE 15: Comparison of transverse stiffness of piers with different service life under different conditions of tsunami wave. Lateral stiffness of pier after (a) HXB-3 action, (b) HXB-4 action, and (c) HXB-5 action.

different service life. Finally, it is worth noting that the first failure location is in the lower compressive strength (splash zone) of the protective layer under vertical loading, which indicates that the compressive strength of the protective layer is one of the main factors affecting the vertical bearing capacity.

(2) When the bridge structure is impacted by tsunami waves under different conditions, the decline rate of the vertical bearing capacity of the pier in service for 0 years $(0 \% \sim 21.1 \%)$ is much larger than that of the lateral bearing capacity $(0 \% \sim 11.45 \%)$, which indicates that the pier concrete has a higher impact on the vertical bearing capacity of the structure after tension and compression damage. The main reason is that the transverse bearing capacity of the pier is primarily caused by the tensile effect of longitudinal reinforcement, and the vertical bearing capacity results from the compressive effect of concrete.

(3) The structural damage factors of bridge piers with different service life after being impacted by different conditions of tsunami wave include two parts: one is the durability damage caused by steel corrosion, and the other is the impact damage caused by the tsunami wave. When both of them act at the same time, it was evident that the damage to the structure was more remarkable, even more significant than the 
TABle 9: Comparison of lateral stiffness results.

\begin{tabular}{|c|c|c|c|c|c|c|}
\hline Lateral stiffness $(\mathrm{kN} / \mathrm{m})$ & 0 years & 10 years & 20 years & 30 years & 40 years & 50 years \\
\hline \multirow{2}{*}{ No wave } & 61241 & 60209 & 58411 & 57473 & 56046 & 54607 \\
\hline & $-0 \%$ & $-1.7 \%$ & $-4.6 \%$ & $-6.2 \%$ & $-8.5 \%$ & $-10.8 \%$ \\
\hline \multirow{2}{*}{ HXB-3 } & 57600 & 54989 & 53301 & 52857 & 48791 & 47217 \\
\hline & $-6.0 \%$ & $-10.2 \%$ & $-13.0 \%$ & $-13.7 \%$ & $-20.3 \%$ & $-22.9 \%$ \\
\hline \multirow{2}{*}{ HXB-4 } & 55277 & 54566 & 52304 & 50984 & 47717 & \multirow{2}{*}{ Destruction } \\
\hline & $-9.7 \%$ & $-10.9 \%$ & $-14.6 \%$ & $-16.8 \%$ & $-22.5 \%$ & \\
\hline HXB-5 & $\begin{array}{c}54766 \\
-10.6 \%\end{array}$ & $\begin{array}{c}53046 \\
-13.4 \%\end{array}$ & $\begin{array}{c}51944 \\
-15.2 \%\end{array}$ & $\begin{array}{c}47460 \\
-22.5 \%\end{array}$ & Destruction & Destruction \\
\hline
\end{tabular}

Note. The ratio is the value of the lateral stiffness of the damaged pier compared with that of the undamaged pier.

damage ratio caused by the two alone. Therefore, it is inaccurate to evaluate the damage of offshore structures only by a single factor or simply superimposing multiple damage factors.

5.2.3. Lateral Stiffness Analysis of Corroded Pier before and after Wave Impact. Through the analysis of pier pushover, the lateral stiffness of piers with different service life under different tsunami wave conditions is obtained. The results are shown in Figure 15 and Table 9.

As shown in Figure 15 and Table 9, the results are as follows:

(1) With the increase of service life of piers, the lateral stiffness of corroded piers after tsunami wave impact decreases faster than that of corroded piers without tsunami wave impact. Especially after service 30, the decrease ratio of stiffness is much larger than that in service (0 20) years, and even the pier is damaged, indicating that the durability damage caused by corrosion is pronounced.

(2) After 30 years of service, the lateral bearing capacity and stiffness of piers are reduced by $27.6 \%$ and $6.2 \%$, respectively, due to corrosion. Without considering corrosion, the lateral bearing capacity and stiffness of bridge piers are reduced by $11.45 \%$ and $10.6 \%$, respectively, after HXB-5 wave impact. Under the combined action of corrosion and HXB-5 wave impact, the lateral bearing capacity and stiffness of bridge piers are reduced by $41.8 \%$ and $22.5 \%$, respectively, after 30 years of service, which is more prominent than that of a single factor or simple superposition of two factors. With the increase of service life, this trend is more obvious and more prone to structural damage, which also shows a coupling effect under the action of multiple factors, and it cannot only consider single factor or simple superposition of multiple factors.

\section{Conclusion}

This paper studies the influence of multiple degradations on the seismic performance of offshore piers from the perspective of tsunami wave impact, chloride ion corrosion, and their interaction. The major conclusions are as follows:
(1) The time history analysis of shear force and moment under the action of tsunami wave shows that when the submergence coefficient of the tsunami wave is 1.01 , the influence of wave velocity on the horizontal component of wave force is greater than that of vertical force. When the impact submergence coefficient is greater than or equal to 2 , there is no significant difference in the peak shear force at the bottom of the pier under different impact submergence coefficients. Therefore, the relationship between the horizontal component of wave force and the impact submergence coefficient is not monotonically increasing, but the peak moment at the bottom of the pier increases obviously, which indicates that the influence of the vertical component of wave force on the moment at the bottom of the pier is more important to a certain extent.

(2) Through the analysis of the bearing capacity of corroded piers before and after wave impact, it is shown that the transverse bearing capacity and vertical bearing capacity decrease by $48.2 \%$ and $16.1 \%$, respectively, from 0 to 50 years without wave action. Therefore, it is very necessary to consider the corrosion environment of piers when evaluating offshore bridges. In addition, compared with the transverse bearing capacity, the decline rate of the vertical bearing capacity of the pier is lower in different service life. When the bridge structure is impacted by tsunami wave under different conditions, the decline rate of vertical bearing capacity $(0 \% \sim 21.1 \%)$ of the pier in service for 0 years is much larger than that of its transverse bearing capacity $(0 \% \sim 11.45 \%)$, which indicates that the influence of pier concrete on the vertical bearing capacity of the structure is greater after being damaged by tension and compression.

(3) Through the analysis of the bearing capacity and lateral stiffness of corroded piers before and after wave impact, it is shown that the factors causing the decline of bearing capacity and lateral stiffness of piers with different service life under different conditions of tsunami wave impact include two parts: one is the degradation of material properties caused by pier corrosion, and the other is the impact damage caused by the tsunami wave. Under the combined action of corrosion and wave impact, the 
reduction ratio of transverse bearing capacity and stiffness of pier is obviously larger than that of a single factor or simple superposition of two factors. With the increase of service life, this trend is more noticeable and more prone to failure. It is proved that there is a coupling effect under the action of multiple factors. Therefore, in practical engineering, only a single factor or simple superposition of multiple factors cannot be considered.

In the numerical simulation, this paper only considers the transverse (incident wave direction) and vertical damage of the bridge caused by wave impact. However, the wave may have a certain impact on the longitudinal direction of the bridge, which can be further studied in the future.

\section{Data Availability}

The data used to support the findings of this study are available from the corresponding author upon request.

\section{Conflicts of Interest}

The authors declare that there are no conflicts of interest regarding the publication of this study.

\section{Acknowledgments}

This work was supported by the National Natural Science Foundation of China (Grant no. 51578157) and Fujian Science and Technology Program Guiding Project (Grant no. 2009Y004).

\section{References}

[1] G. Jia and P. Gardoni, "State-dependent stochastic models: a general stochastic framework for modeling deteriorating engineering systems considering multiple deterioration processes and their interactions," Structural Safety, vol. 72, pp. 99-110, 2018.

[2] D. You, M. F. Dan, and D. Saydam, "Time-variant sustainability assessment of seismically vulnerable bridges subjected to multiple hazards," Earthquake Engineering \& Structural Dynamics, vol. 42, no. 10, pp. 1451-1467, 2013.

[3] G. Zhang, P. Wang, M. Zhao, X. Du, and X. Zhao, "Seismic structure-water-sediment-rock interaction model and its application to immersed tunnel analysis under obliquely incident earthquake," Tunnelling and Underground Space Technology, vol. 109, no. 2, Article ID 103758, 2021.

[4] P. Wang, Y. Xu, X. Zhang, R. Xi, and X. Du, "A substructure method for seismic responses of offshore wind turbine considering nonlinear pile-soil dynamic interaction," Soil Dynamics and Earthquake Engineering, vol. 144, Article ID 106684, 2021.

[5] G. Cuomo, M. Tirindelli, and W. Allsop, "Wave-in-deck loads on exposed jetties," Coastal Engineering, vol. 54, no. 9, pp. 657-679, 2007.

[6] A. Guo, Q. Fang, X. Bai, and H. Li, "Hydrodynamic experiment of the wave force acting on the superstructures of coastal bridges," Journal of Bridge Engineering, vol. 20, no. 12, 2015 .
[7] Q. Fang, R. Hong, A. Guo, and H. Li, "Experimental investigation of wave forces on coastal bridge decks subjected to oblique wave attack," Journal of Bridge Engineering, vol. 24, no. 4, 2019.

[8] H. He, R. Li, and K. Chen, "Durability evolution of RC bridge under coupling action of chloride corrosion and carbonization based on DLA model," Mathematical Problems in Engineering, vol. 2015, Article ID 951846, 11 pages, 2015.

[9] J. Jia, L. Zhao, S. Wu, X. Wang, Y. Bai, and Y. Wei, "Experimental investigation on the seismic performance of lowlevel corroded and retrofitted reinforced concrete bridge columns with CFRP fabric," Engineering Structures, vol. 209, Article ID 110225, 2020.

[10] M. Akiyama, D. M. Frangopol, and H. Ishibashi, "Toward lifecycle reliability-, risk- and resilience-based design and assessment of bridges and bridge networks under independent and interacting hazards: emphasis on earthquake, tsunami and corrosion," Structure and Infrastructure Engineering, vol. 16, no. 1, pp. 26-50, 2020.

[11] W. Y. Dong, C. Q. Fang, S. Yang, and Z. J. Yuan, “Analysis on effect factors of lateral anti-impact properties of the reinforced concrete pier in ocean environment (press in Chinese)," Concrete, vol. 12, pp. 58-62, 2017.

[12] Y. Lin and J. F. Zhao, "Effect of non-uniform corrosion on seismic performance of RC piers (press in Chinese)," Low Temperature Architecture Technology, vol. 12, pp. 43-46+68, 2019.

[13] M. T. Stephens, A. Winter, M. R. Motley, and D. E. Lehman, "Comparing seismic and tsunami load demands on reinforced concrete and concrete filled steel tube bridges," in Proceedings of the 39th IABSE Symposium-Engineering the Future, Vancouver, Canada, September 2017.

[14] J. liu, "Research on the seismic performance of RC bridge with local corrosion of reinforced bar (press in Chinese)," ME Thesis, Zhejiang University, Hangzhou, China, 2016.

[15] X. F. Li, "Seismic risk probability assessment of offshore bridge based on the material performance degradation (press in Chinese)," ME Thesis, Fuzhou University, Fuzhou, China, 2018.

[16] K. A. T. Vu and M. G. Stewart, "Structural reliability of concrete bridges including improved chloride-induced corrosion models," Structural Safety, vol. 22, no. 4, pp. 313-333, 2000.

[17] C. H. Lu, Y. X. Zhao, and W. L. Jin, "Modeling of time to corrosion-induced cover cracking in reinforced concrete structures (press in Chinese)," Journal of Building Structures, vol. 31, no. 2, pp. 85-92, 2010.

[18] M. Otieno, H. Beushausen, and M. Alexander, "Chlorideinduced corrosion of steel in cracked concrete - Part I: experimental studies under accelerated and natural marine environments," Cement and Concrete Research, vol. 79, pp. 373-385, 2016.

[19] J. Ghosh and J. E. Padgett, "Aging considerations in the development of time-dependent seismic fragility curves," Journal of Structural Engineering, vol. 136, no. 12, pp. 1497-1511, 2010.

[20] M. M. Kashani, A. J. Crewe, and N. A. Alexander, "Nonlinear stress-strain behaviour of corrosion-damaged reinforcing bars including inelastic buckling," Engineering Structures, vol. 48, pp. 417-429, 2013.

[21] D. Coronelli and P. Gambarova, "Structural assessment of corroded reinforced concrete beams: modeling guidelines," Journal of Structural Engineering, vol. 130, no. 8, pp. 1214-1224, 2004. 
[22] ABAQUS, ABAQUS Version 6.16 Analysis User's Manuals, Dassault Systemes Simulia Corporation, Providence, RI, USA, 2016.

[23] GB50010-2010. Design Code for concrete Structure (press in Chinese), China Construction Industry Press, Beijing, China, 2015.

[24] B. Huang, Z. Yang, B. Zhu, J. Zhang, A. Kang, and L. Pan, "Vulnerability assessment of coastal bridge superstructure with box girder under solitary wave forces through experimental study," Ocean Engineering, vol. 189, Article ID 106337, 2019.

[25] D. S. Wang, Q. M. Feng, and G. X. Wang, "Analysis model of pounding between adjacent bridge girders during earthquakes based on collinear impact between rods (press in Chinese)," Engineering Mechanics, vol. 21, no. 2, pp. 157-166, 2004.

[26] Z. G. Sun, H. N. Li, D. S. Wang, and D. J. Si, "Discrimination criterion governing flexural-shear failure modes and improved seismic analysis model for RC bridge piers (press in Chinese)," China Journal of Highway and Transport, vol. 28, no. 6, pp. 42-50, 2015. 